Cómo citar este trabajo: Fraile-Jurado, P., \& Fernández-Díaz, M. (2018). Análisis e interpretación de la distribución espacial de banderas de España y simbología religiosa en los balcones del municipio de Sevilla. Boletín de la Asociación de Geógrafos Españoles, 81, 2769, 1-34. http://dx.doi.org/10.21138/bage.2769

\title{
Análisis e interpretación de la distribución espacial de banderas de España y simbología religiosa en los balcones del municipio de Sevilla
}

Analysis and interpretation of the spatial distribution of flags of Spain and religious symbols on the balconies of the municipality of Seville

\author{
Pablo Fraile-Jurado \\ pfraile@us.es \\ Miguel Fernández-Díaz \\ migfedi@gmail.com \\ Departamento de Geografía Física y A.G.R. \\ Universidad de Sevilla (España)
}

\section{Resumen}

Durante los últimos años se ha intensificado el fenómeno de colgar banderas de España en balcones de domicilios particulares en diferentes ciudades españolas, llegando a su máximo a finales de 2017 durante la escala de tensión de la crisis institucional en Cataluña. En este trabajo se identifican los patrones espaciales de la distribución de banderas de España y de simbología religiosa en los balcones del municipio de Sevilla, analizando a continuación su relación con los resultados electorales de las últimas elecciones al Parlamento Andaluz, y con otras variables socioeconómicas. Los resultados indican una clara correlación con la ideología de los votantes, identificándose correlaciones positivas con respecto al voto al PP y Vox y negativas con respecto al voto a Adelante Andalucía y al PSOE.

Palabras clave: banderas; nacionalismo; simbología religiosa; espacialización; análisis multivariante. 


\begin{abstract}
In recent years Spanish flags have been hanged on balconies of private homes in different Spanish cities, reaching its peak at the end of 2017 during the tensest days of the institutional crisis in Catalonia. This paper identifies the spatial patterns of the distribution of Spanish flags and religious symbols on the balconies of the municipality of Seville, analyzing their relationship between the electoral results of the last elections to the Andalusian Parliament and other socioeconomic variables. The results indicate a strong correlation with the ideology of the voters, identifying positive correlations with respect to the vote to the PP and Vox, and negative with respect to the vote to Adelante Andalucía and PSOE.
\end{abstract}

Key words: flags; nationalism; religious symbology; spatialization; multivariate analysis.

\title{
1 Introducción
}

El uso de las banderas tiene una larga trayectoria, iniciado en la Antigüedad en diferentes localizaciones como Roma (vexiles) o China con fines principalmente militares, para agrupar a todos aquellos que combaten bajo un mismo mando. Aunque el surgimiento de la heráldica en la Edad Media influyó en la complejidad y el colorido de los diseños, el concepto de bandera llegó a Occidente en el siglo XII, procedente de China a través de la influencia que los pueblos de Oriente Medio tuvieron sobre los cruzados (Cadenas \& Vicent, 1976). Más adelante, y fuera del simbolismo religioso o militar, las banderas fueron empleadas asiduamente en la navegación. No es hasta las revoluciones francesa y norteamericana, a finales del siglo XVIII, cuando la bandera adquiere una carga simbólica, ideológica y emotiva acentuada (Jaskulowski, 2016), tanto por parte de los Estados como por parte de movimientos obreros, sindicatos o partidos políticos, más adelante.

El empleo del estándar de simbología nacional como elemento aglutinador entre individuos y diferenciador del resto, asumido por diferentes países como elemento de representación nacional, es un fenómeno generalizado ya en el siglo XIX, cuando todos los estados parecen asumir la necesidad de dicha representación. Con el desarrollo del estado contemporáneo, y sus diferentes niveles administrativos, se produce, especialmente durante el siglo XX, la generación de nuevos símbolos regionales y municipales, en el caso de la estructura administrativa española equiparable a cualquier otro territorio.

Más allá de la evidente función de la bandera como elemento de representación de un colectivo, asumida por las diferentes constituciones y leyes reguladoras de los territorios, existe una función no administrativa consistente en la representación de sentimientos nacionales. En este sentido, son numerosos los trabajos que han vinculado el empleo de las banderas con la identificación sentimental de diferentes colectivos (Shatz \& Lavine, 2007; Podeh, 2011; Arthur, 2018). 
Particularmente, el desarrollo de nuevas naciones durante el siglo XIX, como EEUU, ha ido vinculado a un empleo consistente por parte de las diferentes administraciones, generando un fuerte sentimiento identitario entre la población y la bandera (Eriksen \& Jenkins, 2007). Se trataría de un fenómeno de culto a la bandera que, según Jaskulowski (2016), se inicia a principios del siglo XIX con fines militares, y se difunde entre la población ante la secuencia de eventos bélicos. Este fenómeno identitario, reconocido ampliamente en la literatura científica asociada a este tema, no se acepta tan explícitamente, por parte de ninguna de las instituciones que destinan fondos públicos a la distribución de simbología nacional o de cualquier otro nivel administrativo, aparentemente por asumirse que la generación de un sentimiento identitario ha de surgir como un fenómeno espontáneo y no dirigido desde diferentes instituciones.

La situación se torna aún más compleja cuando se trata de banderas ampliamente reconocidas no vinculadas a ninguna administración existente, ya sea con la intención de convertirse en una de ellas, como las esteladas catalanas, de reivindicaciones puramente políticas (bandera por el acercamiento de los presos vascos) o con fuertes raíces históricas de los derrotados en una guerra tanto con pretensiones políticas (bandera republicana española) como sin ellas (bandera confederada de EEUU, bandera imperialista japonesa). La actitud de los diferentes estados en los que conviven este tipo de fenómenos ha sido muy diversa: desde la ausencia de reconocimiento oficial de dichas banderas y de los sentimientos asociados a estas, en el caso de la estelada, a la estricta delimitación espacial de su uso, como el caso de la bandera confederada estadounidense, que solo puede estar presente en cementerios militares (Coski, 2005), por considerarse un símbolo de segregación racial (Thornton, 1996). Aún más restrictiva resulta la legislación alemana, cuyo código penal sanciona el uso de simbología de organizaciones inconstitucionales, para impedir la exhibición de simbología nazi.

En el caso particular español, es preciso señalar que se trata de una situación profundamente compleja que aún debe ser estudiada en profundidad desde diferentes ámbitos. El fenómeno del nacionalismo español es anterior a la propia generalización del uso de la bandera, y parece encontrar su orígenes a finales del siglo XVIII (Varela, 1994). En la actualidad y a diferencia de otros estados, en España existe una profunda correlación entre la ideología y el afecto por los símbolos nacionales. La izquierda en España ha mostrado una clara desafección por la simbología nacional constitucional, que especialmente durante las dos últimas décadas ha sido asimilada por la derecha como simbología propia (Navarro Ardoy, 2016), y que parece estar vinculada parcialmente en tiempos recientes a un fenómeno de respuesta a las intenciones secesionistas de parte de la sociedad catalana. Según Navarro Ardoy (2016), diferentes autores han reseñado que la ausencia de un patriotismo nacional en la izquierda española parece estar más vinculado con la apropiación de este fenómeno por parte de la derecha (Muñoz, 2012). 
El presente trabajo pretende estudiar el fenómeno de aparición de banderas de España en balcones de viviendas particulares que se ha producido durante el último lustro, y que alcanzó su máximo durante los últimos días de 2017. Es preciso recordar que esos fueron los días previos a las elecciones catalanas del 21 de diciembre de 2017, las primeras elecciones tras los acontecimientos de septiembre y octubre de 2017, en los que el President de la Generalitat de Catalunya declaró unilateralmente la independencia de Cataluña, suspendida indefinidamente durante las fechas del trabajo de campo. El incremento de banderas esteladas y españolas en Cataluña fue tal que se llegó a hablar en la prensa de "Guerra de las Banderas" (Figura 1). Asimismo, en el resto del territorio nacional se produjo un evidente incremento del número de banderas españolas, como respuesta nacionalista española a la crisis política que se estaba viviendo en Cataluña (2017, October 27, en La Vanguardia). En un estudio aún no publicado avanzado a la prensa (Ramón, 2017, November 4, en Expansión), miembros de la Universidad de Comillas indicaron la existencia de un componente de imitación de los vecinos a la hora de colgar las banderas en balcones, al ser la bandera de España un símbolo con fuertes connotaciones. Si bien es un fenómeno que prácticamente no ha sido estudiado desde el ámbito académico-y aún menos desde su perspectiva espacial y geográfica- prácticamente todos los diarios de tirada nacional se han hecho eco del papel aparentemente ideologizado que parece jugar la bandera española en la política nacional en tiempos recientes, ya sea desde la mera descripción del fenómeno (Cebrián Echarri, 2017, November 10, en El País), de desigual implementación territorial y que en territorios como Galicia apenas ha sido significativo (Capéans, 2018, October 14, en La Voz de Galicia) a un análisis político más favorable a dicha exhibición (López, 2018, June 2, en ABC de Sevilla) o crítico con las posibles incoherencias del aparente patriotismo que denotan (Hernández, 2018, October 18, en eldiario.es).

Pese a que la exhibición de banderas españolas en los balcones y ventanas de los domicilios de poblaciones españolas fue un fenómeno que aparentemente alcanzó su máximo a finales de 2017, ha seguido presente en la mayor parte del territorio, acuñándose la expresión "la España de los balcones" (Pareja, 2018, December 17, en Diario de Jerez; Europa Press, 2019, February 10, en eldiario.es) para denotar a la parte de las sociedad española descontenta con el secesionismo catalán, y desde mayo de 2018, con la gestión del Presidente Pedro Sánchez de esta crisis.

El uso del espacio público como marco de reivindicación política por parte de diferentes ideologías a través de diferentes tipos de símbolos ha sido abordado a menudo, como es el caso de el País Vasco (Rodríguez Fouz, 2009), donde el posicionamiento frente al terrorismo (mediante el uso de lazos azules en los años 90 y primera década de 2000) o la reivindicación por el acercamiento de presos etarras se escenificó en el espacio público mediante señas de identidad inequívocas, a las que Rodríguez Fouz señala como combativas. 
Figura 1. Titular de El País del día 16 de octubre de 2017

\section{$\equiv$ EL PAİS}

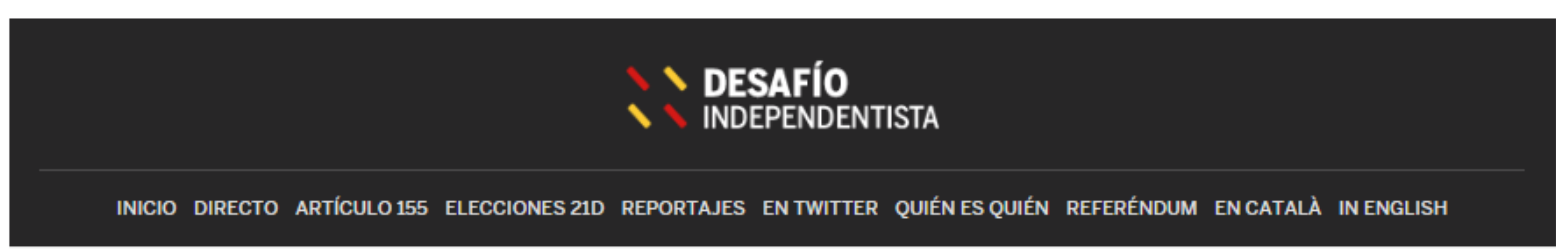

\section{La guerra de las banderas}

Vivimos una vuelta atrás, el fracaso de la integración y el triunfo del imperio del miedo

\section{(1) (-):}

ANTONIO NAVALÓN

16 OCT 2017 - 00:00 CEST

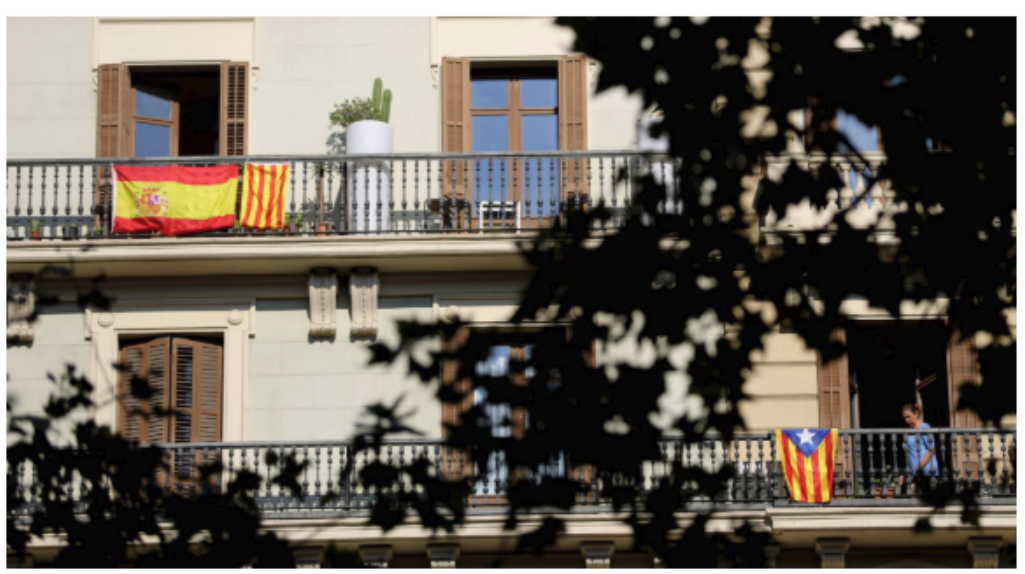

Banderas espanola, catalana y la estelada, en Gran Via de les Corts, en Barcelona. @ SAMUEL SANCHEZ

Los años siguientes a la II Guerra Mundial sirvieron no solo para reconstruir los antídotos democráticos contra la tentación totalitaria, sino para ampliar las

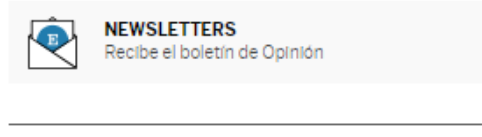

\section{TE PUEDE INTERESAR}

Grandeza parlamentaria en medio del naufragio politico del Brexit

Contra la superstición nacionalista la historia

Santalucia AM pasa al ataque en fondos y aspira a gestionar 8.000 millones
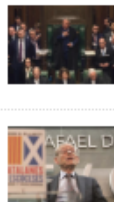

Asi te hemos contado las elecciones andaluzas y las reacciones tras los resultados
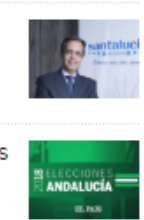

Fuente: Navalón (2017, October 16) en El País

Aunque la cuestión de la simbología religiosa apenas ha ocupado espacio en noticias y aún menos en ámbitos académicos, se puede afirmar que durante los últimos años ha existido un incremento del número de estandartes de Jesús y otro tipo de simbología religiosa en los balcones de los domicilios particulares en España, cuando se aproximan las fechas navideñas. De acuerdo con algunas noticias publicadas dentro del espectro de los medios de comunicación de tendencia conservadora en España (Daniele, 2017, June 5, en $A B C$ ) como según asociaciones como el Observatorio para la Libertad Religiosa y de Conciencia, en sus informes tanto de 2016 (publicado en 2017) como de 2017 (en 2018), los ataques a la libertad religiosa, fundamentalmente cristiana y católica, se han incrementado durante los últimos años. No obstante, es preciso señalar que dentro de la cuantificación que se realiza anualmente por parte de esta asociación -que determina parcialmente la orientación de la opinión pública católica, al ser recogidos sus informes por 
numerosos medios de comunicación conservadores- se incluyen como ataques la petición de derogación contra los acuerdos con la Santa Sede en el Parlamento de Murcia, que los concejales no asistan como cargos públicos (por parte de los grupos municipales de Compromís, Izquierda Unida y Podemos), o la aparición de supuesta simbología satánica en una caseta de obras en Getafe (informe de 2017). En cualquier caso y aunque no se cita expresamente en los informes de esta asociación, parte de las motivaciones en la exhibición de simbología religiosa en los balcones de la viviendas en España se explica como una respuesta a estos supuestos ataques, tal y como sí se ha afirmado en otros medios, en los que se ha recalcado "la creciente necesidad de los cristianos de manifestar el sentido genuino de la Navidad ante las corrientes laicistas que pretenden desvirtuar el significado de estas fiestas" (Ponte, 2008, December 26, en Huelva Información). No obstante, es preciso recalcar que otros medios de comunicación próximos al catolicismo en España han animado a campañas de exhibición de estandartes de Jesús en los balcones sin que se haga referencia a ataques de origen laico (Sara Arias, 2011, December 13, en El Comercio).

Sin embargo y como se ha indicado con anterioridad, existen pocas referencias académicas en torno a la cuestión de la simbología religiosa en la España contemporánea, estando la mayoría de ellas centradas en el plano jurídico. En este sentido, cabe destacar que según Cañamares Arribas (2006, 2009, 2010) la mayoría de los conflictos y por tanto de las situaciones que generan necesidad de regulación jurídica en cuanto a la simbología religiosa provienen de situaciones derivadas de la inmigración ("el respeto de determinadas horas de descanso semanal, el de ciertas prescripciones alimenticias y, desde luego, el empleo de prendas religiosas como el foulard islámico[" en Cañamares Arribas, 2006), en el aparente choque entre libertad religiosa y la convivencia social, especialmente dentro del ámbito de los menores. Los conflictos analizados por Cañamares Arribas tienden a ocurrir en torno a la religión islámica, debido fundamentalmente a que en el momento del desarrollo jurídico español, con la Constitución Española de 1978 (que en su artículo 16 reconoce la libertad religiosa "sin más limitación, en sus manifestaciones, que la necesaria para el mantenimiento del orden público protegido por la Ley " como marco principal) la sociedad española era considerablemente diferente de la actual en cuanto a su composición étnica.

El objetivo de este trabajo es identificar e interpretar la existencia de patrones espaciales en la distribución de banderas de España y simbología religiosa en las viviendas del municipio de Sevilla, e interpretar sus causas socioelectorales.

\section{2 Área de estudio: el comportamiento electoral interno del municipio de Sevilla}

El área de estudio de este trabajo es el municipio de Sevilla. El municipio de Sevilla es la capital de Andalucía, tiene una población de casi 700000 habitantes y se encuentra ubicado en la Vega del río Guadalquivir. Está atravesado por este río, quedando dividido en dos áreas de desigual 
tamaño: la mayor parte del municipio al este, y los barrios de Triana y Los Remedios, al oeste del río.

Con la intención de contextualizar el trabajo, se realizará una breve descripción espacial de los resultados electorales de las elecciones al Parlamento Andaluz celebradas el 2 de diciembre de 2018. Estos resultados mostraron que el partido más votado en el municipio fue el PSOE, con un $25,26 \%$ de los votos, seguido por Adelante Andalucía (18,89\%), Ciudadanos (18,8\%) y Partido Popular (18,78\%). A más distancia se situó Vox (12,36 \%). La participación fue del 63,07\%.

\section{Figura 2. Participación por distritos en las elecciones al Parlamento Andaluz de 2018}

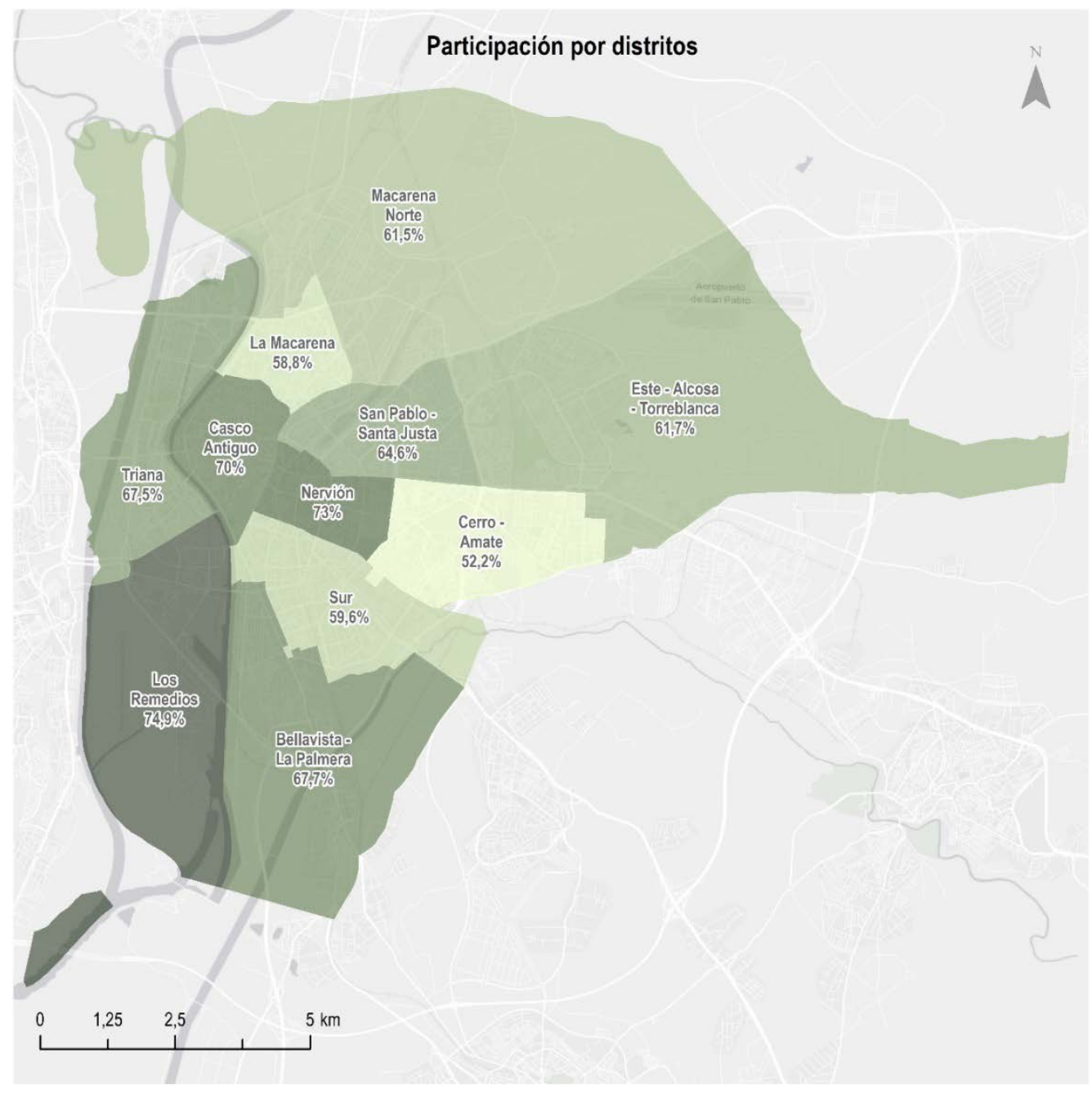

Fuente: elaboración propia

La evolución histórica de este núcleo de población muestra una clara relación con la distribución espacial de diferentes aspectos socioeconómicos y demográficos. Sevilla está dividida administrativamente en 11 distritos (Figura 2), entre los que se reparten las aproximadamente tres mil calles del municipio. El distrito Casco Antiguo se corresponde con el casco histórico de la ciudad, coincidiendo aproximadamente con el área amurallada a finales en el siglo XIII. Se trata de un área de calles intrincadas que denotan la ausencia de planificación propia del entramado urbano 
musulmán, y de una compleja historia. Su población es de unos 60000 habitantes. Se trata de una población envejecida, si bien se han identificado potentes fenómenos de gentrificación en tiempos recientes (Díaz Parra, 2009), y con alto poder adquisitivo en relación al resto del municipio (Figura 3). Ideológicamente, la mayor parte de los votos en este distrito han sido de tendencia conservadora a lo largo de las últimas décadas, aunque en las elecciones al Parlamento Andaluz de 2018 la segunda fuerza más votada fue AA $(20,16 \%)$ tras el PP $(26,32 \%)$. Cabe destacar que el PSOE obtuvo en este distrito su segundo peor resultado de todo el municipio, con un 13,92\%, siendo la quinta fuerza más votada.

Al norte de este distrito de encuentra el distrito Macarena, con 75000 habitantes, desarrollado sobre parte del arrabal más antiguo de la ciudad. Junto con el distrito anterior, se trata del distrito de menor tamaño, con una población más joven y con la mayor cantidad de inmigrantes, alcanzando casi un 10 \% (Torres et al., 2011). Históricamente la mayoría de los votos han sido para el PSOE-A, si bien en las últimas elecciones la diferencia entre este partido y la coalición de izquierda Adelante Andalucía se acortó significativamente, sumando ambas fuerzas un 51 \% de los votos.

Aún más al norte se halla el distrito Norte, de mayor tamaño que los anteriores, aunque incluye algunas zonas de cultivo. Su población es de unos 70000 habitantes, y está conformado por barrios obreros construidos mayoritariamente desde la década de los 70 y 80, algunos de los cuales presentan evidentes síntomas de degradación paisajística, y cierta conflictividad social. Se trata de uno de las poblaciones con menor poder adquisitivo de Sevilla, destacando el gran asentamiento chabolista de El Vacie (Torres Gutiérrez, 2011). Al igual que en el distrito anterior, el voto en este distrito es tradicionalmente socialista, sumando entre PSOE-A y AA un $61 \%$ de los votos en las últimas elecciones. Se trata del distrito con la renta per cápita más baja del municipio, por debajo de $17000 €$ (Figura 3).

Al este del distrito Casco Antiguo se sitúa el de San Pablo-Santa Justa. Con 66000 habitantes, se trata de un distrito diverso con edificaciones posteriores a los años 70. El resultado electoral en las elecciones andaluzas de 2018 fue muy semejante al del resto del municipio.

Más al este, abarcando un área aún mayor se sitúa el distrito Este-Alcosa-Torreblanca. Se trata del distrito más poblado de Sevilla, con 153000 habitantes, e integra el núcleo urbano de Torreblanca, históricamente segregado espacialmente de Sevilla, pero ya perteneciente al mismo conjunto urbano. Es un área de gran diversidad socioeconómica. Aunque la fuerza más votada fue el PSOE-A (28\%), obtuvo un $6 \%$ menos de votos que en el resto de la ciudad, de manera semejante al PP (11\% de los votos, un 7\% menos que en el resto del municipio). AA y Cs, sin embargo, obtuvieron mejores resultados ( $+6 \%$ y $+2 \%$ respectivamente) que en el resto del municipio. 
Al sur de los distritos anteriores se encuentran dos distritos con características muy diferentes. En el distrito de Nervión, caracterizado por unas rentas superiores, con 51000 habitantes, el PP fue el partido más votado $(30,9 \%)$, seguido de cerca por Cs $(22,95 \%)$ y Vox $(15,95 \%)$ a más distancia. PSOE y AA fueron las opciones menos votadas dentro de las cinco candidaturas con representación en el Parlamento Andaluz. El distrito Cerro-Amate tiene unos 90000 habitantes y está conformado mayoritariamente por habitantes pertenecientes a clases populares, presentando rentas más bajas que el promedio del municipio. Como en los distritos con características socioeconómicas semejantes, se produjo una victoria del PSOE-A (39,1\% de los votos), seguido de lejos por AA (23\%). Los resultados de Cs $(14,2 \%)$, PP $(8,8 \%)$ y Vox $(7,7 \%)$ son significativamente bajos.

El Distrito Sur tiene 75000 habitantes, y está compuesto por barrios profundamente desiguales, incluyendo barrios de las élites económicas de la ciudad (El Prado, Santa Genoveval) y barrios muy degradados (La Oliva, Las Letanías) e incluso marginales, como los barrios de Martínez Montañez Murillo, entre otros, conocidos popularmente como las 3000 Viviendas. El comportamiento electoral en estos barrios, por tanto, fue muy heterogéneo, registrándose un resultado muy semejante entre los dos partidos más votados, PSOE-A $(23,84 \%)$ y PP $(22,38 \%)$. En este distrito, Vox obtuvo algunos votos más que AA (15 votos de diferencia, lo que supuso un 15,12 \% frente a 15,08\%). Cabe destacar que en los días siguientes a las elecciones se registraron en los medios de comunicación algunas informaciones erróneas, en las que atribuían a Vox un mejor resultado electoral que al PSOE, en particular en las 3.000 Viviendas, siendo este dato erróneo, puesto que en esas mesas electorales triunfó el PSOE por una amplia mayoría, sumando junto con AA más del $75 \%$ de los votos.

En el distrito de Bellavista-La Palmera, con 35000 habitantes, se invirtió el orden con respecto a muchos de los distritos anteriores, con una situación de empate entre PP y Cs, que sumaron algo más del $20 \%$ de los votos cada uno. En este distrito Vox fue la cuarta fuerza más votada, por delante de AA.

Al otro lado del río, en Triana (49 000 habitantes), se produjo la victoria del PP con un 23,7\% de los votos por un 23,23 \% de los votos del PSOE-A. Al sur de Triana se encuentra el distrito de Los Remedios, con solo 27000 habitantes, y con una de las rentas más altas de Sevilla (Figura 3). Se trata del distrito habitado por la población con mayor poder adquisitivo y con una ideología tradicionalmente más conservadora. En elecciones relativamente recientes, como las andaluzas de 2012, el PP venció con un 81\% de los votos. En 2018 se ha mantenido esta tendencia, aunque fragmentándose el voto conservador en torno a tres partidos: el PP fue la fuerza más votada, con un $37,7 \%$ de los votos, seguida de Vox $(24,66 \%)$ y Cs $(21,1 \%)$. Cabe destacar que la suma de PSOE $(8,37 \%)$ y AA $(5,35 \%)$ no llega al $14 \%$ de los votos totales. 
En cuanto a la participación, cabe destacar que se situó en un 63,07\%, un $5 \%$ menos que en las elecciones de 2015, aunque por encima del 58 \% total de Andalucía. La distribución por distritos fue espacialmente irregular (Figura 2). En los distritos de voto mayoritariamente conservador, la participación se situó incluso por encima de las elecciones de 2015, destacando Los Remedios con un $74,8 \%$ y Nervión con un $73 \%$.

\section{Figura 3. Renta per cápita por distritos postales en el municipio de Sevilla}

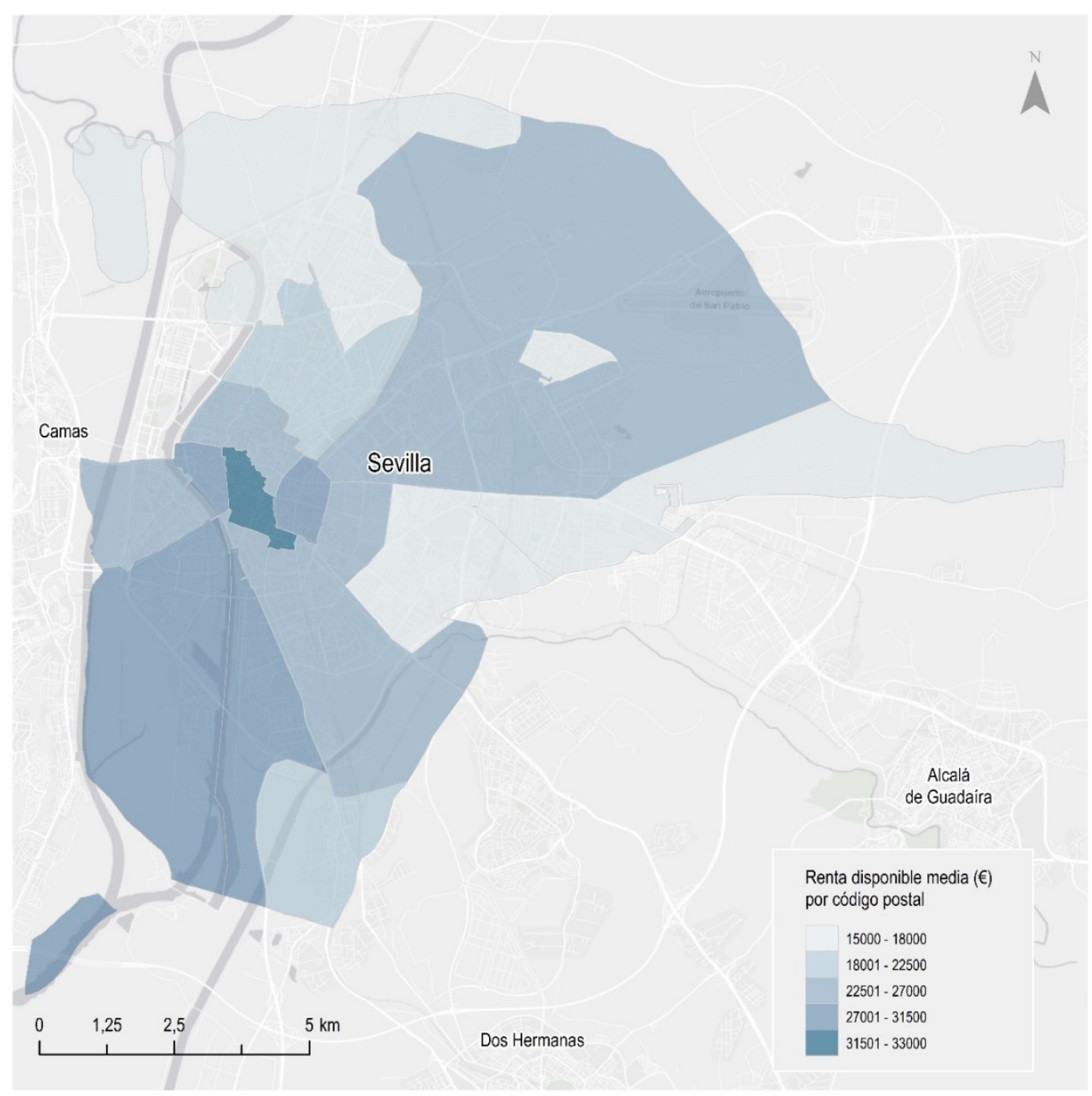

Fuente: elaboración propia

\section{Datos y métodos}

El presente trabajo se realizó en dos fases. En la primera fase se realizó un muestreo del número de banderas y estandartes por calle del municipio de Sevilla. Para la elección de las calles del trabajo de campo, se realizó una selección del 5 \% del total del callejero del municipio, manteniendo esta proporción en cada uno de los once distritos de municipio de Sevilla (Figura 4). En la segunda fase se realizaron análisis estadísticos multivariantes para interpretar la distribución espacial de ambos símbolos en el municipio. 
El trabajo de campo fue realizado en los días 18, 19 y 20 de diciembre de 2017, debido a un aparente pico alto en el número de banderas de España en los balcones de las viviendas en muchos municipios españoles, aparentemente vinculado a la situación políitica en Cataluña.

Figura 4. Calles muestreadas en el trabajo de campo

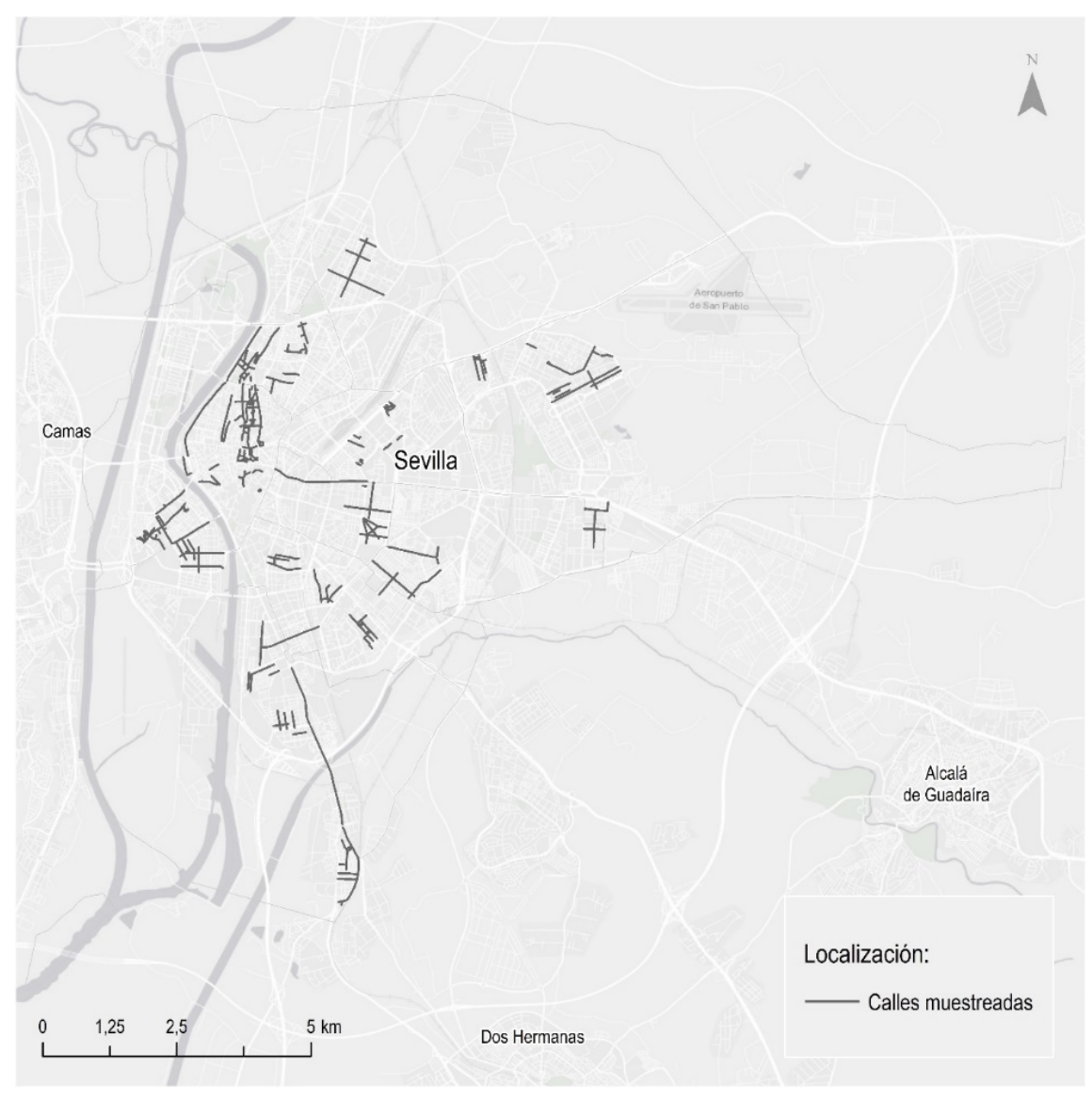

Fuente: elaboración propia

Por otra parte, es preciso destacar que en algunos municipios españoles, en las fechas previas a la Navidad y durante la misma, es común encontrar balcones con paños con imágenes religiosas, especialmente la bandera roja oscura con la imagen de Jesús niño, y con el lema "Jesús ha nacido" (en adelante, "estandarte de Jesús").

Tanto las banderas españolas como las banderas de Jesús mostraban formatos levemente distintos, con diferentes tonalidades cromáticas (el amarillo de la bandera de España oscilaba del amarillo puro (\#FFFFOO en el código hex de colores) al amarillo oro (\#FFD700), y diferentes tipologías y ornamentos en el caso de la bandera de Jesús. Asimismo, no todas las banderas nacionales identificadas fueron expresamente constitucionales, identificándose como válidas las banderas con escudo monárquico, "lisas" (sin escudo alguno) e incluso con el toro de Osborne. 
Figura 5. Ejemplo de banderas de España y estandartes de Jesús objeto del recuento

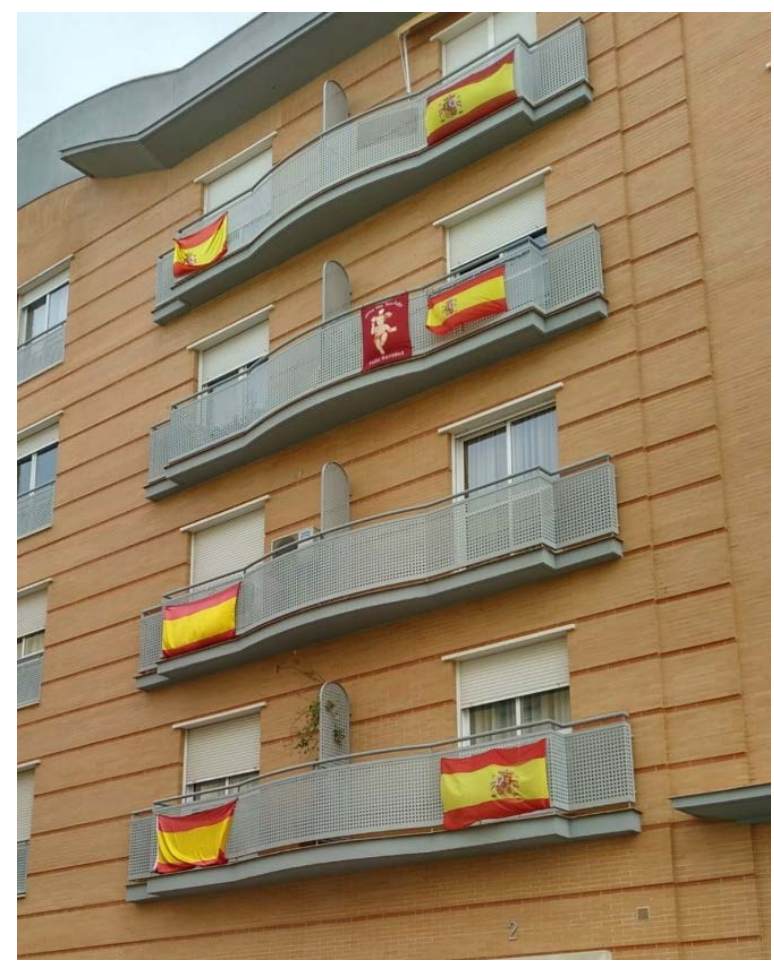

Fuente: elaboración propia

El trabajo de campo se realizó desde vehículo privado con dos personas, cuantificando calle por calle a partir de las rutas seleccionadas el número de banderas de España y el número de banderas de Jesús. Se descartó el uso de cámaras que permitiesen un recuento automático dada la complejidad del software necesario para realizar dicho recuento, al ser muchas de las calles espacios comerciales con amplia variedad cromática, y haber trabajado en condiciones muy variables de luminosidad, siendo por tanto muy confusas para una cuantificación automática. Se realizaron diferentes pruebas de recuento en gabinete a partir de los vídeos grabados con el sensor GoPro Hero 3.0, que permite la grabación de vídeo en 4K, pero el elevado número de errores obligaba a numerosos revisionados del vídeo y a realizar varias tomas por calle, optándose definitivamente por el recuento manual con conductor y copiloto. El uso de un vehículo se justifica debido a la necesidad de cubrir un área lo más amplia posible en poco tiempo. En cualquier caso, para verificar que el recuento resultó correcto se revisaron diferentes calles del distrito Casco Histórico de Sevilla peatonalmente, obteniéndose los mismos resultados, por lo que el método de recuento fue validado. Se excluyeron las banderas en edificios institucionales y comerciales.

Una vez recogidos los datos de las 152 calles acerca del número de banderas y de estandartes de Jesús, se filtraron los mismos, eliminando todas aquellas calles con un número de viviendas inferior a 5 independientemente del número de banderas o estandartes identificados (en la mayoría de los casos, cero), debido a las necesidades de los análisis estadísticos realizados, quedando un total de 
132 casos. Se obtuvo el valor medio de banderas de España y estandartes por habitante y vivienda para cada calle muestreada.

A partir de estos registros se realizó una cartografía de ambas variables mediante la interpolación de los datos obtenidos por calle, con la intención de facilitar su visualización e interpretación de la distribución espacial. Puesto que la muestra resultaba lo suficientemente amplia (más de un $5 \%$ de las calles de Sevilla) y bien distribuida (ver Figura 3), se realizó una interpolación espacial por el método del vecino próximo, contenido en el paquete Spatial Analyst de ArcGls 10.3 para ambas variables.

Adicionalmente, y con la intención de observar las diferencias en la distribución entre ambas variables, se restaron los grids correspondientes a las dos interpolaciones realizadas mediante una sencilla operación de álgebra de mapas en Map Calculator de ArcGIS 10.3, obteniendo una superficie de diferencias a partir de la cual se elaboró un tercer mapa.

La segunda fase del trabajo consistió en la realización de un análisis multivariante, consistente tanto en el cálculo cruzado de la intensidad de la correlación entre variables como en la elaboración de modelos de regresión lineal múltiple. Para estos análisis se emplearon tres tipos de variables (Tabla 1): a) resultados electorales en las Elecciones al Parlamento Andaluz de diciembre de 2018, b) tamaño y valor medio de la vivienda por calle y distrito, respectivamente, c) características socioeconómicas de la población perteneciente a cada mesa electoral, y d) en el caso del municipio de Sevilla, la población residente por calle.

Los datos referentes a los resultados electorales en cada mesa fueron obtenidos directamente a partir de la información proporcionada por la propia Junta de Andalucía sobre los resultados electorales. Cada calle puede pertenecer a varias mesas electorales, y cada mesa a su vez suele contener varias calles. Por ello, a cada calle se asignó un único colegio electoral, integrando los datos de cada mesa electoral de las que componen un colegio. De este modo, cada calle analizada contuvo al menos una muestra de los resultados electorales asociados a dicha calle. Por ello, en el caso de calle contiguas, o simplemente localizadas dentro del ámbito de un mismo distrito electoral, los valores iniciales sobre los resultados electorales asociados a dichas calles fueron idénticos.

La información sobre el tamaño medio de la vivienda por calle se obtuvo a través del análisis de la base de datos de Catastro. Sin embargo, no se empleó esta fuente para el valor medio de la vivienda por estar el valor de venta aparentemente más próximo a la economía real (Sentencia 843/2018 del tribunal Supremo, de 23 de mayo de 2018). La información socioeconómica se obtuvo a partir de la información del Padrón Municipal de 2017 (INE, 2018).

La información acerca del número de habitantes por calle fue crítica y ha condicionado el ámbito de trabajo, puesto que solo está disponible para el municipio de Sevilla, a través de su Mapa 
estratégico de Ruidos (Ayuntamiento de Sevilla, 2016, anexo IV). Esta variable permite relativizar el número de elementos por calle, permitiendo un análisis mucho más profundo y realista. De hecho, el trabajo de campo se realizó inicialmente durante dos días más y abarcó otros once municipios del área metropolitana de Sevilla, pero al ser imposible relativizar el número de banderas o estandartes por calle (la diversidad de tipologías urbana no aconsejaba emplear la longitud de la calle como variable útil en este sentido), se eligió el municipio de Sevilla como único área de estudio.

El siguiente paso para preparar los datos para el análisis multivariante consistió en relacionar el número de banderas y estandartes con la población total y el número de viviendas existentes, obteniéndose de este modo un indicador relativo (número de banderas y estandartes por habitante o vivienda) que permitió tratar de manera homogénea todos los datos, que pasaron a ser de este modo o bien porcentajes, o bien estadísticos de tendencia central.

Tal y como aparece recogido en la Tabla 1, el ámbito de mayor extensión empleado fue el del barrio, para tres variables, y los de mesa electoral o calle para el resto. Este nivel de detalle impidió el empleo de otras variables aparentemente muy explicativas de fenómenos sociales, como la renta, pero que muestran un nivel de agregación superior (en el caso de la renta, el distrito postal).

Tabla 1. Variables utilizadas en el análisis multivariante

\begin{tabular}{|l|l|l|l|l|}
\hline \multicolumn{1}{|c|}{ VARIABLES } & \multicolumn{1}{|c|}{ ÁMBITO } & \multicolumn{1}{c|}{ TIPO } & \multicolumn{1}{c|}{ FUENTE } \\
\hline 1 & Banderas por habitante & Calle & Relativo & Campo \\
\hline 2 & Banderas por vivienda & Calle & Relativo & Campo \\
\hline 3 & Estandartes por habitante & Calle & Relativo & Campo \\
\hline 4 & Estandarte por vivienda & Calle & Relativo & Campo \\
\hline 5 & Voto a PSOE & Mesa & Porcentaje & $\begin{array}{l}\text { Resultados } \\
\text { electorales }\end{array}$ \\
\hline 6 & Voto a AA & Mesa & Porcentaje & $\begin{array}{l}\text { Resultados } \\
\text { electorales }\end{array}$ \\
\hline 7 & Voto a PP & Mesa & Porcentaje & $\begin{array}{l}\text { Resultados } \\
\text { electorales }\end{array}$ \\
\hline 8 & Voto a Cs & Mesa & Porcentaje & $\begin{array}{l}\text { Resultados } \\
\text { electorales }\end{array}$ \\
\hline 9 & Voto a Vox & Mesa & Porcentaje & $\begin{array}{l}\text { Resultados } \\
\text { electorales }\end{array}$ \\
\hline 10 & Voto a otros partidos & Mesa & Porcentaje & $\begin{array}{l}\text { Resultados } \\
\text { electorales }\end{array}$ \\
\hline 11 & Participación & Mesa & Porcentaje & $\begin{array}{l}\text { Resultados } \\
\text { electorales }\end{array}$ \\
\hline 12 & Precio medio de la vivienda & Calle & Promedio & Fotocasa \\
\hline 13 & Tamaño medio de la vivienda & Calle & Promedio & Catastro \\
\hline 14 & Nivel de estudios & Barrio & Porcentaje & Padrón \\
\hline
\end{tabular}


Tabla 1. Continuación

\begin{tabular}{|l|l|l|l|l|}
\hline \multicolumn{1}{|c|}{ VARIABLES } & \multicolumn{1}{|c|}{ ÁMBITO } & \multicolumn{1}{c|}{ TIPO } & \multicolumn{1}{c|}{ FUENTE } \\
\hline 15 & Proporción de mujeres & Barrio & Porcentaje & Padrón \\
\hline 16 & Mayores de 65 años & Barrio & Porcentaje & Padrón \\
\hline 17 & Habitantes por calle & Calle & Absoluto & $\begin{array}{l}\text { Mapa estratégico } \\
\text { de Ruido }\end{array}$ \\
\hline
\end{tabular}

Fuente: elaboración propia

Con la intención de interpretar el fenómeno de las banderas y estandartes en los balcones, se elaboró una matriz de correlaciones a partir de las variables de la Tabla 1 en la que se calculó el valor del coeficiente de correlación de Pearson entre cada variable mediante el software estadístico SPSS 23.0.

El método empleado para la elaboración de modelos consistió en una regresión lineal múltiple por pasos. La ventaja de este método, frente al resto de métodos de obtención de modelos de regresión lineal múltiple (hacia atrás, hacia adelante...) consiste en que se obtienen diferentes modelos asociados a distintas iteraciones, permitiendo elegir el número de variables independientes, y por lo tanto modelos de mayor o menor complejidad.

\section{Resultados y discusión}

En las calles visitadas se identificaron un total de 1178 banderas de España y 578 estandartes de Jesús. Las tres calles con más banderas de España se encontraron en Los Remedios, con 269, 209 y 110 (República Argentina, Virgen de Luján y Virgen de La Cinta). En cuanto a las calles con más estandartes de Jesús, se encontraron dos en Los Remedios (República Argentina y Virgen de Luján, con 61 y 49 respectivamente) y otra situada fuera de este distrito (calle Reina Mercedes, con 34 estandartes). Todas estas calles son de gran longitud, lo que es preciso considerar a la hora de observar estos resultados.

La proporción de banderas por habitante (Tabla 2) y de estandartes por habitantes (Tabla 2) alcanzan sus valores máximos en varios distritos, si bien se sigue observando una preponderancia de los distritos de Los Remedios y Casco Antiguo, coherente a priori con la interpretación común de relacionar ambos fenómenos con la ideología conservadora de estas áreas observada en los resultados electorales. Asimismo, es preciso resaltar que en calles como Virgen de Luján, con 0,73 banderas por habitante, existen casi 2 banderas por vivienda, al calcularse una población por vivienda de 2,3 personas en esta calle. 
Tabla 2. Calles con mayor número de banderas por habitante

\begin{tabular}{|c|l|c|l|}
\hline \multicolumn{1}{|c|}{ CALLE } & $\begin{array}{c}\text { BANDERAS } \\
\text { POR } \\
\text { HABITANTE }\end{array}$ & \multicolumn{1}{|c|}{ DISTRITO } \\
\hline 1 & Virgen De Luján & 0,73 & Los Remedios \\
\hline 2 & Refinadores & 0,59 & Casco Antiguo \\
\hline 3 & Virgen De Aguas Santas & 0,32 & Los Remedios \\
\hline 4 & Bustos Tavera & 0,30 & Casco Antiguo \\
\hline 5 & Reina Mercedes & 0,22 & Sur - La Palmera - Reina Mercedes \\
\hline 6 & República Argentina & 0,21 & Los Remedios \\
\hline 7 & Dr José Manuel Puelle de Santos & 0,20 & Macarena Norte \\
\hline 8 & Pedro Pérez Fernández & 0,19 & Los Remedios \\
\hline 9 & Alborea & 0,17 & San Pablo -Santa Justa \\
\hline 10 & Zumaque & 0,15 & Este \\
\hline
\end{tabular}

Fuente: elaboración propia

Tabla 3. Calles con mayor número de estandartes por habitante

\begin{tabular}{|c|l|c|l|}
\hline \multicolumn{1}{|c|}{ CALLE } & $\begin{array}{r}\text { ESTANDARTES } \\
\text { POR HABITANTE }\end{array}$ & \multicolumn{1}{|c|}{ DISTRITO } \\
\hline 1 & Ponce De León & 0,17 & Casco Antiguo \\
\hline 2 & Virgen De Luján & 0,17 & Los Remedios \\
\hline 3 & Alborea & 0,17 & San Pablo -Santa Justa \\
\hline 4 & Cristo De La Sed & 0,15 & Nervión \\
\hline 5 & San Juan & 0,13 & Casco Antiguo \\
\hline 6 & Reina Mercedes & 0,10 & Sur - La Palmera - Reina Mercedes \\
\hline 7 & San lldefonso & 0,10 & Casco Antiguo \\
\hline 8 & Refinadores & 0,09 & Casco Antiguo \\
\hline 9 & San Juan De La Palma & 0,09 & Casco Antiguo \\
\hline 10 & Virgen De Aguas Santas & 0,08 & Este \\
\hline
\end{tabular}

Fuente: elaboración propia 
Figura 5. Avenida de República Argentina, con 269 banderas de España y 61 estandartes de Jesús

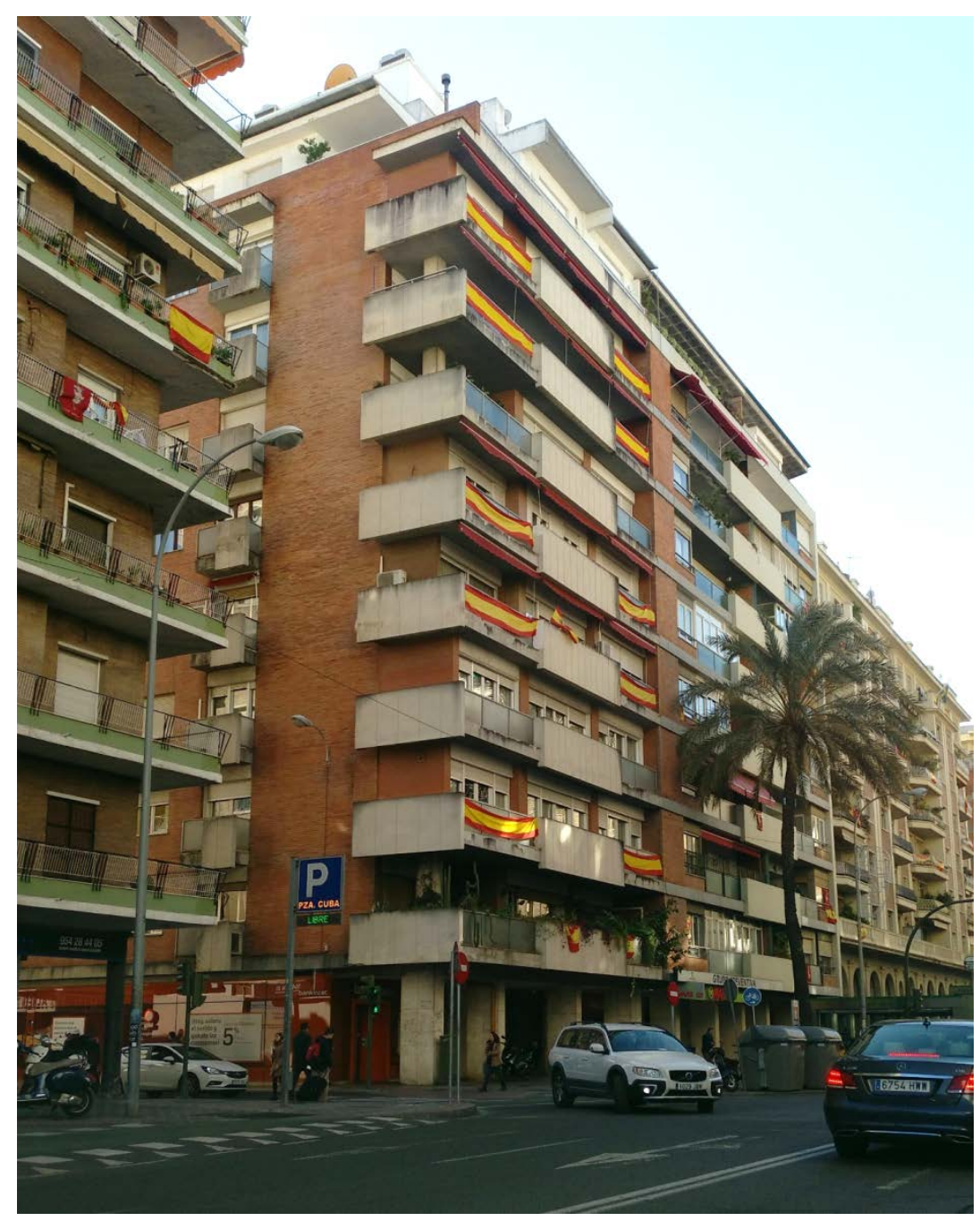

Fuente: elaboración propia

Espacialmente, ambas variables presentan una distribución parecida, si bien se pueden identificar ciertas peculiaridades. En el caso de las banderas de España, existe una clara concentración en torno al barrio de Los Remedios, mostrando además valores muy elevados en el sur del Casco Histórico de Sevilla, y avenidas de La Palmera y Reina Mercedes. El resto del municipio presenta valores homogéneamente bajos, en comparación con los anteriores, habiéndose identificado numerosas calles sin banderas.

En cuanto a la distribución de los estandartes de Jesús, aunque la distribución es semejante a la anterior por presentar sus valores más altos en el entorno del barrio de Los Remedios y la Avenida de Reina Mercedes, más al sur, cabe destacar que esta distribución espacial es mucho más difusa en torno a este barrio, desplazándose además hacia el norte (barrios de Triana, Tardón y Barrio León) y hacia el otro lado del río. En el Caso Histórico de Sevilla se observa una intensa variabilidad espacial que no aparecía con las banderas de España, mostrándose igualmente valores medios en La Macarena, Nervión y Gran Plaza. Pese a que según Deener (2010), la identidad pública de un 
barrio no siempre ha de corresponder con la identidad real de todos sus habitantes, siendo las cuestiones políiticas un ejemplo de opinión tradicionalmente oculta, no parece este el caso de los barrios en los que la simbología estudiada alcanza un mayor protagonismo.

Figura 6. Mapa de densidad de banderas de España en el municipio de Sevilla

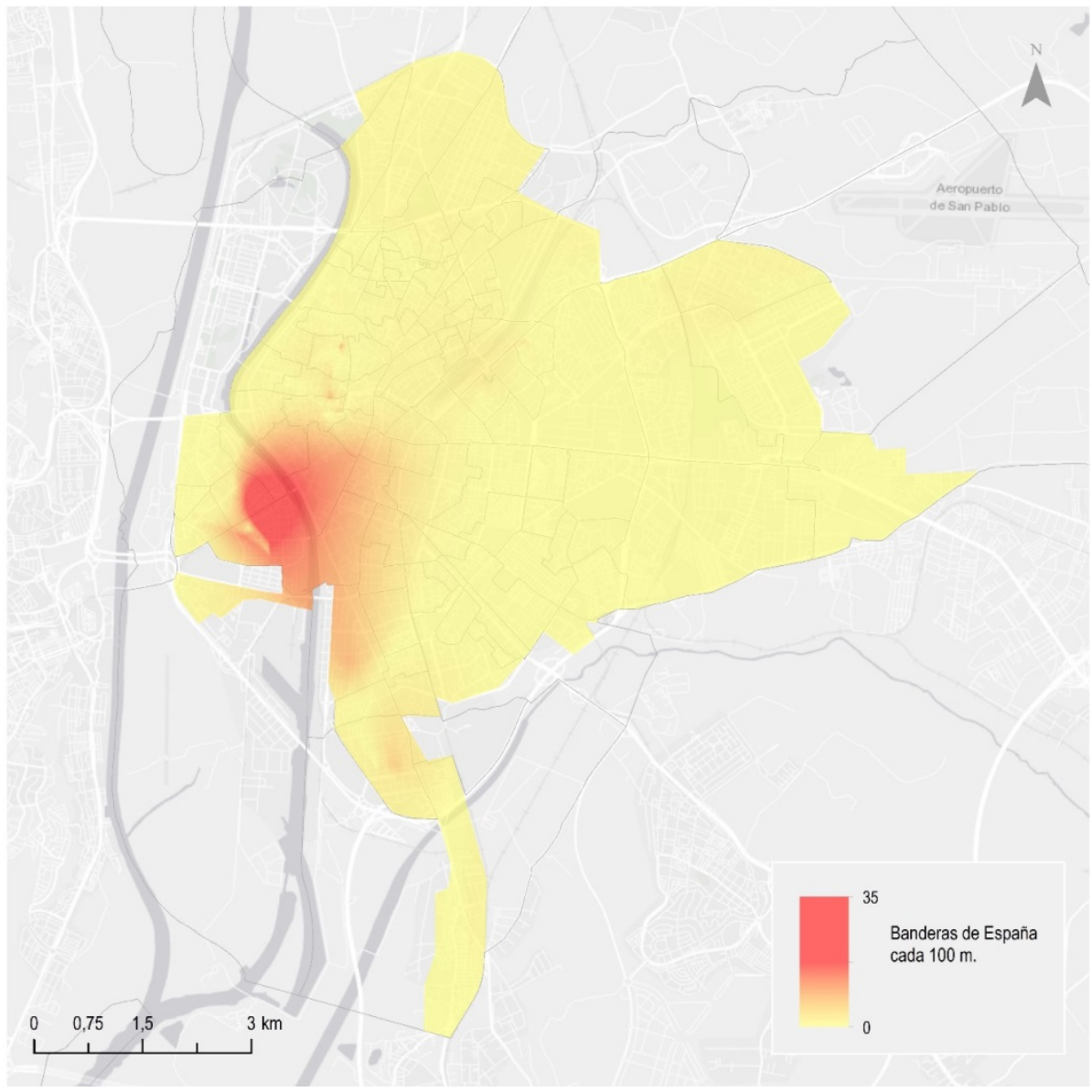

Fuente: elaboración propia

Con respecto al análisis estadístico de las correlaciones con respecto a las variables de la Tabla 1, estas muestran que los valores más intensos entre la variable banderas de España y el resto de variables analizadas, con excepción del estandarte de Jesús, que se tratará posteriormente, responden a cuestiones ideológicas. Así, tal y como aparece en la Tabla 4, la correlación más intensa se da con respecto al voto a Vox (con un coeficiente de correlación de Pearson de $+0,369$ ), y el de Adelante Andalucía (con un coeficiente de correlación de Pearson de -0,279), siendo significativos los resultados obtenidos con respecto al voto al PSOE-A $(-0,22)$, PP $(+0,20)$ y el voto a otros partidos $(-0,19)$. El único partido político con el que no se ha hallado correlación estadísticamente significativa es $\mathrm{Cs}$, si bien cabe destacar que presenta un valor positivo de $+0,146$. En el análisis por vivienda, en lugar de por habitantes, los resultados son semejantes, aunque la correlación identificada es ligeramente más intensa en algunos casos. El hecho de que los resultados muestren correlaciones estadísticamente significativas con cuatro de los cinco partidos 
políticos analizados parece ser coherente con trabajos sobre sociología del voto en España (Caínzos, 2001) en los que se ha remarcado el fuerte componente de clase que desde hace décadas han presentado los resultados electorales.

Figura 7. Mapa de densidad de estandartes de Jesús en el municipio de Sevilla

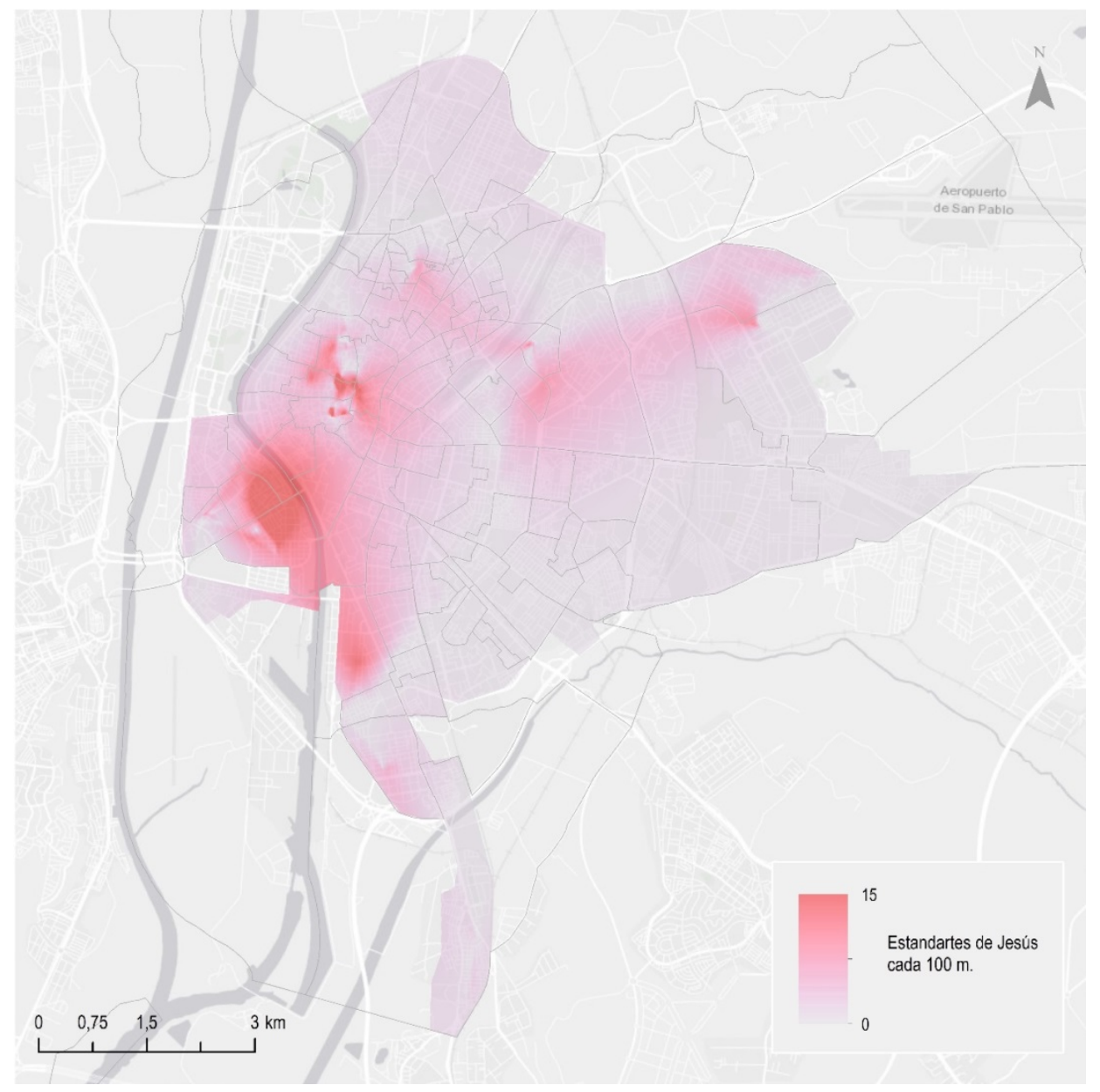

Fuente: elaboración propia

Los resultados obtenidos parecen ser coherentes con las líneas políticas e ideológicas de algunos de los partidos, pero no de todos. De este modo, los discursos de PP, Cs y Vox acerca de la cuestión catalana mostraron un tono duro, que culminó con la aplicación del artículo 155 de la Constitución Española por parte del Gobierno del PP, por el cual se intervino la autonomía de Cataluña durante varios meses. La exhibición de banderas nacionales en los barrios donde estos tres partidos acumulan más votos parece concordar con estas ideas, afines al nacional-catolicismo español (Miralles, 2015). Por otra parte, Podemos e Izquierda Unida, que entre otros integraron la plataforma electoral Adelante Andalucía, se han mostrado radicalmente contrarios a la aplicación de esta medida, proponiendo salidas dialogadas a dicho conflicto. El coeficiente de correlación de Pearson obtenido $(-0,287)$ indica que sus votantes están lejos de este nacionalismo español. Sin embargo, la discordancia parece producirse en cuanto a la exhibición de simbología nacional por 
parte de los votantes del PSOE en Sevilla y las posturas que este partido adoptó en la crisis política existente en España en los días en los que se realizó el trabajo de campo. Al menos en cuanto al fenómeno evaluado en este trabajo, los votantes del PSOE están mucho más cerca de los de AA que de los de las otras tres fuerzas con representación en el Parlamento Andaluz. Los autores son conscientes de que la interpretación de resultados electorales, especialmente si provienen de sondeos, es profundamente compleja (Martínez i Coma \& van Ham, 2009), y de que la mera exhibición de simbología nacional no debería ser la única variable para valorar una cuestión tan compleja y delicada como el sentimiento nacionalista y la posición política con respecto a las decisiones a tomar acerca de la unidad de España. En cualquier caso, parece relevante señalar la aparente discordancia entre el posicionamiento político del PSOE a nivel estatal (favorable a la aplicación del artículo 155 de la Constitución Española en la crisis del otoño de 2017), y la manera en que sus votantes no mostraron banderas españolas desde sus balcones, tal y como se puede afirmar en caso de identificar la presencia de banderas de España en estas fechas con la aplicación el artículo 155 de la Constitución Española.

Tabla 4. Resultados de análisis de correlaciones entre el voto partidos políticos y la distribución entre estandarte y banderas analizadas

\begin{tabular}{|l|c|c|c|c|}
\cline { 2 - 5 } \multicolumn{1}{c|}{} & \multicolumn{2}{c|}{ BANDERAS DE ESPAÑA } & \multicolumn{2}{c|}{ ESTANDARTES DE JESÚS } \\
\cline { 2 - 5 } \multicolumn{1}{c|}{} & POR HABITANTE & POR VIVIENDA & POR HABITANTE & POR VIVIENDA \\
\hline PSOE & $-0,233^{* *}$ & $-0,228^{* *}$ & $-0,188^{*}$ & $-0,193^{*}$ \\
\hline PP & $0,220 * *$ & $0,222 * *$ & $0,216 * *$ & $0,219 * *$ \\
\hline CS & 0,146 & 0,140 & 0,109 & 0,120 \\
\hline AA & $-0,279 * *$ & $-0,287 * *$ & $-0,227 * *$ & $-0,243 * *$ \\
\hline VOX & $0,369 * *$ & $0,373 * *$ & $0,224 * *$ & $0,247 * *$ \\
\hline OTROS & $-0,196 *$ & $-0,198 *$ & $-0,144$ & $-0,153$ \\
\hline PARTICIP & $0,250 * *$ & $0,253 * *$ & 0,109 & 0,128 \\
\hline
\end{tabular}

Leyenda: ** significancia estadística a un nivel de 0,01. * significancia estadística a un nivel del 0,05.

Fuente: elaboración propia

Con respecto a los estandartes de Jesús, los resultados son semejantes a los anteriores. La identificación entre el voto a Vox y el número de estandartes de Jesús es menos intensa, aunque sigue siendo de las más elevadas de las analizadas (coeficiente de correlación de Pearson de $0,224)$. En este caso es la correlación con el voto a Adelante Andalucía la que muestra un valor ligeramente más intenso en el análisis de estandartes por habitante $(-0,227)$. En el caso del voto al 
PSOE solo es significativo a un nivel de 0,05. La correlación entre la cantidad de estandartes con la participación no es significativa para los niveles de significación de estadística empleados, si bien mantiene, como en el caso de las banderas de España, un signo positivo, indicando que cuanto mayor fue la participación por calle, más banderas por habitante o vivienda se encontraron.

La interpretación de los resultados debe ser realizada con suma cautela. Aparentemente, tanto la distribución espacial de los estandartes de Jesús, mucho más numerosas en los barrios de predominio de voto a partidos situados en la derecha del espectro político, como los resultados obtenidos a partir del análisis de correlaciones entre las diferentes variables empleadas en este trabajo, sugerirían que hay muchos católicos entre los votantes de derecha y muy pocos entre los de izquierda. Sin embargo, y pese a que la tendencia general se aproxime a esta interpretación, en estudios realizados con anterioridad (CIS, 2013) se identificó que en España, aproximadamente un $91 \%$ de los votantes del PP se declaraban católicos (lo cual resulta coherente con los resultados mostrados en el trabajo), por un 70,3\% de los votantes del PSOE y un 46,2\% de los votantes de Izquierda Unida, partido que compone la coalición electoral de AA. En cuanto a la implicación con la religión por parte de los votantes, el mismo estudio del CIS señalaba claras diferencias entre izquierda y derecha, pero que en cualquier caso no permiten interpretar correctamente los resultados presentados en este trabajo. El 21,5\% de los votantes del PP afirmaron ir a misa una vez por semana, por un $10,1 \%$ de los del PSOE y un 7,6\% de los de IU. Pese a que existen diferencias importantes, la proporción de banderas observadas en uno y otro barrio, y sobre todo la correlación inversa encontrada entre el voto a PSOE o AA y la exhibición de estandartes de Jesús no se corresponden con los resultados del barómetro del CIS de 2013. Se trata, por tanto, no tanto de cuántos católicos simpatizan con cada partido, sino del modo en que lo hacen. Así como, según Navarro Ardoy (2016), los partidos políticos y electores de derecha parecen hacer hecho suya la bandera española, podría considerarse que los electores de derecha también han hecho lo propio con la simbología religiosa. De todos modos, este fenómeno tampoco sería suficiente para explicar la distribución de ambas variables dentro del plano del municipio de Sevilla, puesto que las proporciones de votos obtenidas por cada partido en cada distrito no se corresponden con la proporción de banderas de España y estandartes de Jesús encontradas en el distrito de Los Remedios. Así pues, la exhibición de ambos símbolos podría tratarse de un fenómeno que, partiendo de unas claras connotaciones ideológicas, va más allá y en parte debido a la imitación (según apuntaban Martínez y Valor en el artículo en prensa publicado en el diario Expansión el 4 de noviembre de 2017) y posiblemente debido a algún otro tipo de fenómeno basado en el orgullo o identidad de barrio. Este fenómeno ha sido ampliamente estudiado en múltiples facetas (Haeberle, 1987; Bernardo \& Palma-Oliveira, 2016), el empleo de una simbología común ha sido destacado por diferentes autores (Smith, 1984; Hull et al., 1994), destacando en España trabajos en los que se destaca la construcción de la identidad de barrio a partir del empleo frecuente de 
una simbología común por parte de la comunidad LGTB (Enguix, 2009). En cualquier caso, para poder verificar esta afirmación será necesario realizar un trabajo de campo más profundo que incluya encuestas con preguntas acerca de las motivaciones de los vecinos para exhibir o no exhibir las banderas y estandartes analizados.

Los resultados obtenidos acerca de la correlación con diferentes variables sociodemográficas muestran correlaciones menores que la anteriores (Tabla 5). Únicamente se encuentran correlaciones estadísticamente significativas entre la distribución de banderas por habitante (o por vivienda) y el nivel de estudios, y entre el precio de la vivienda y la colocación de estandartes de Jesús, evidenciando un intenso componente ideológico tanto en el caso de las banderas como en el los estandartes de Jesús. En cualquier caso, el signo de las correlaciones es positivo en todas las variables (nivel de estudios, precio de la vivienda), excepto en el caso de la población mayor de 65 años, en el que es ligeramente negativo, presentando en cualquier caso valores muy lejanos a ser significativos.

La cuestión acerca de la correlación positiva entre el nivel de estudios y la exhibición de banderas de España resulta especialmente llamativa, puesto que resulta frecuente observar cómo a menudo en redes sociales se tiende a deslegitimar posiciones políticas de extrema derecha aduciendo un nivel cultural más bajo. Sin que se pretenda en este trabajo asumir que el nivel cultural se corresponde estrictamente con el nivel de estudios, parece que la realidad resulta muy diferente a este tipo de asunciones. Los resultados descritos en el municipio de Sevilla parecen coincidir con un modelo de sociedad caracterizado por una importante polarización explicada por cuestiones socioculturales e ideológicas, con ciertas analogías a sociedades latinoamericanas (Cannon, 2008) o a la descrita por Palonen en Hungría (2009), en las que las clases obreras tienen un menor acceso a los estudios y una clara identificación posiciones de izquierda, mientras que existe una burguesía de mayor éxito económico, de ideología conservadora.

El hecho de que los coeficientes de correlación de Pearson obtenidos resulten en cualquier caso, relativamente bajos (pese a haber muchas relaciones significativas, ninguna de las presentadas en las Tablas 4 y 5 alcanza un valor de 0,5) podría estar explicado por las propias características del análisis realizado y las limitaciones del análisis de correlaciones (Taylor, 1990). Es preciso considerar que se han realizado análisis entre variables absolutas, que pueden alcanzar cualquier valor entre $\mathrm{O}$ e infinito (el número de banderas de España o el número de estandartes por habitante y vivienda) con variables relativizadas, como el porcentaje de votos a cada partido, con valores acotados entre 0 y 100, siendo por tanto $100 \%$ el valor máximo posible para el voto a cada partido. Adicionalmente, habría que considerar que el propio hecho de exhibir la bandera en el domicilio propio no está exento de una pequeña inversión económica. Aunque es frecuente la venta de banderas en establecimientos de bajo coste, una bandera de un tamaño visible desde el suelo 
suele suponer un desembolso mínimo de 5 euros. Es posible que independientemente de la ideología y las ganas de reivindicar la ideología propia, determinados hogares en los barrios con menores ingresos del municipio decidieran no realizar una inversión que podría entenderse como superflua frente a otros gastos del hogar, aún más teniendo en cuenta que el trabajo de campo se realizó en fechas muy próximas a la Navidad. Asimismo, y especialmente en el barrio de Los Remedios, fueron numerosos los balcones y domicilios en los que se identificaron varias banderas por balcón, mientras que en barrios de la periferia urbana, con menores ingresos medios, este fenómeno fue extremadamente raro.

Tabla 5. Resultado del análisis de correlaciones entre variables sociodemográficas y la distribución entre estandarte y banderas analizadas

\begin{tabular}{|l|c|c|c|c|}
\cline { 2 - 5 } \multicolumn{1}{c|}{} & \multicolumn{2}{c|}{ BANDERAS DE ESPAÑA } & \multicolumn{2}{c|}{ ESTANDARTES DE JESÚS } \\
\cline { 2 - 5 } \multicolumn{1}{c|}{} & POR HABITANTE & POR VIVIENDA & $\begin{array}{c}\text { POR } \\
\text { HABITANTE }\end{array}$ & $\begin{array}{c}\text { POR } \\
\text { VIVIENDA }\end{array}$ \\
\hline Estudios & $0,192^{*}$ & $0,186 *$ & 0,104 & 0,106 \\
\hline Precio vivienda & 0,113 & 0,114 & $0,331^{*}$ & $0,294^{*}$ \\
\hline Mayores de 65 & $-0,024$ & $-0,023$ & 0,045 & 0,029 \\
\hline Vivienda cedida & 0,012 & 0,031 & $-0,035$ & $-0,038$ \\
\hline Mujeres & 0,186 & 0,185 & 0,03 & 0,055 \\
\hline Con hipoteca & $-0,065$ & $-0,093$ & $-0,089$ & $-0,093$ \\
\hline Habitantes por vivienda & $-0,019$ & 0,121 & $-0,128$ & $-0,078$ \\
\hline
\end{tabular}

Leyenda: ** significancia estadística a un nivel de 0,01. * significancia estadística a un nivel del 0,05.

Fuente: elaboración propia

Ambos fenómenos (banderas de España y estandartes de Jesús) presentan una correlación significativa en su distribución espacial, siendo frecuentes observarlos juntos (Figuras 4 y 9). La correlación entre banderas de España y estandartes de Jesús es de 0,511 si se analiza por habitante, y de 0,488 si se analiza por vivienda, siendo ambas significativas a un nivel de confianza de 0,01 .

Sin embargo, y a la vista de las propias Figuras 6 y 7, dicha distribución dista mucho de ser idéntica. Al restar los resultados de los grids empleados para la representación espacial de ambas variables (Figura 8) se observa cómo en el área de estudio existe una clara concentración de banderas de España sobre los estandartes de Jesús en el área de Los Remedios. Pese a que precisamente en ese barrio se han identificado los valores más altos de exhibición de estandartes por habitante, la cantidad de banderas multiplica a los estandartes religiosos, resultando de este 
modo la diferencia observada en la Figura 8. En el resto del municipio los valores son bastante parejos entre ambas variables, con un ligero predominio de la simbología religiosa en la zona este de la ciudad. Este fenómeno explicaría cómo la correlación entre ambas variables, siendo elevada, no es cercana a 1. Los habitantes de este sector de la ciudad, sin embargo, y pese a mostrar un elevado grado de exhibición de sus creencias religiosas, parecen encontrar mayores motivaciones políticas que religiosas, a diferencia del resto de los votantes conservadores en la ciudad, de acuerdo con los análisis realizados. En cualquier caso, este mapa ha de ser interpretado con cierta cautela, puesto que la existencia de valores cercanos a $\mathrm{O}$ no ha de significar ausencia de banderas o estandartes (como es frecuente en la periferia de la ciudad), sino idéntico protagonismo de ambas. Asimismo, se pueden observar ciertas aberraciones, especialmente en el Casco Histórico, que se han generado como resultado del método de interpolación empleado y de las características de las calles en este sector: al existir una gran densidad de calles de poca longitud, fue frecuente encontrar calles con valor 0 tanto en banderas como en estandartes. Sin embargo, la presencia de algunas banderas en calles muy poco pobladas (algo también común en la inspección realizada durante el trabajo de campo) provocó la aparición aberraciones espaciales, observables tanto en la Figura 7 como especialmente en la 8.

Figura 8. Diferencias en la distribución de banderas por habitante y estandartes por habitante

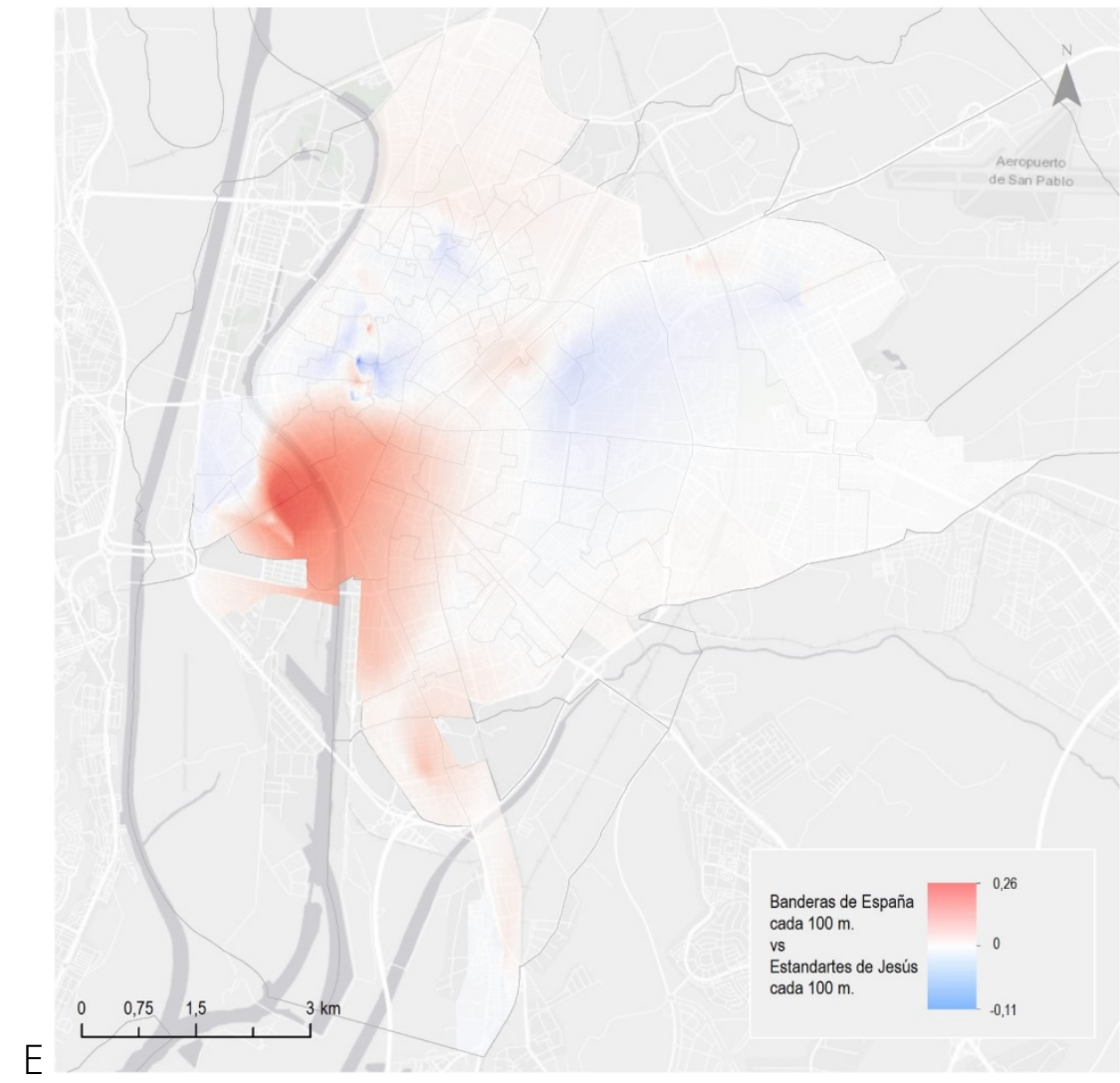

Fuente: elaboración propia 
Uno de los objetivos de este trabajo consistió en tratar de estimar un modelo que interpretase la distribución espacial de las banderas de España a partir de análisis de regresión múltiple. Para ello, y a partir de las variables expuestas en la Tabla 1 se realizaron diferentes aproximaciones empleando métodos que ofrece este el software estadístico SPSS 23.0 (por pasos, hacia delante y hacia atrás). Los resultados obtenidos para las banderas de España están sintetizados en la Tabla 6 y resultan coherentes con el resto del trabajo desarrollado, eligiéndose como principales variables explicativas el voto a Vox, el voto al PP y la presencia de mayor de 65 años. En el caso de los estandartes de Jesús (Tabla 7), todas las iteraciones realizadas a partir de los métodos ofrecidos por el software empleado llegaron a la misma propuesta de elegir como única variable explicativa el porcentaje de votos a Vox.

Tabla 6. Modelos de regresión lineal múltiple sobre la cantidad de banderas de España por habitante elaborados mediante diferentes métodos.

\begin{tabular}{|l|c|c|c|}
\hline \multirow{2}{*}{ MÉTODO } & \multicolumn{2}{|c|}{ Coeficientes no estandarizados } \\
\cline { 2 - 4 } & & B & Error estándar \\
\hline \multirow{4}{*}{ Hacia atrás. Iteración 11 } & (Constante) & 0,015 & 0,043 \\
\cline { 2 - 4 } & PP & 0,006 & 0,002 \\
\cline { 2 - 4 } & Mayores de 65 & $-0,004$ & 0,002 \\
\cline { 2 - 4 } & R & \multicolumn{2}{|c|}{0,446} \\
\cline { 2 - 4 } & R cuadrado & \multicolumn{2}{|c|}{0,199} \\
\hline \multirow{3}{*}{ Por pasos } & (Constante) & $-0,028$ & 0,041 \\
\cline { 2 - 4 } & VOX & 0,007 & 0,003 \\
\cline { 2 - 4 } & R & \multicolumn{2}{|c|}{0,1450} \\
\cline { 2 - 4 } & R cuadrado & \multicolumn{2}{|c|}{} \\
\hline
\end{tabular}

Fuente: elaboración propia

Tabla 7. Modelos de regresión lineal múltiple sobre la cantidad estandartes de Jesús por habitante elaborados mediante diferentes métodos.

\begin{tabular}{|c|c|c|c|}
\hline \multirow{2}{*}{ MÉTODO } & & \multicolumn{2}{|c|}{ Coeficientes no estandarizados } \\
\hline & & B & Error estándar \\
\hline \multirow{4}{*}{$\begin{array}{c}\text { Varios (hacia atrás, hacia delante, } \\
\text { por pasos) }\end{array}$} & (Constante) & 0,000 & 0,013 \\
\hline & VOX & 0,002 & 0,001 \\
\hline & $\mathrm{R}$ & \multicolumn{2}{|c|}{0,328} \\
\hline & R cuadrado & \multicolumn{2}{|c|}{0,108} \\
\hline
\end{tabular}

Fuente: elaboración propia 
Adicionalmente a lo expuesto, los autores quieren señalar la existencia de un fenómeno que la metodología aplicada no permite detectar, pero que ha sido observado con frecuencia durante el trabajo de campo. Se trataría de un aparente fenómeno de imitación, por el cual vecinos de un mismo edifico o calle, en idéntica situación socioeconómica y aparente intención de voto, se verían animados a colocar banderas o estandartes a partir de observar a otros vecinos hacer lo mismo, generándose situaciones como la que se observa en la Figura 9, en la que se identifican hasta 12 elementos colgados en un edificio (ocho banderas de España y cuatro estandartes) por ninguno en el edificio de enfrente, sin que se aprecie diferente tipología urbanística o constructiva, ni una distancia relevante entre ambos. Este tipo de situaciones fueron frecuentes en el trabajo de campo, lo que ratifica la afirmación realizada por Martínez y Valor (2017, November 4, en Expansión) acerca del fenómeno de imitación. Este fenómeno, observado en numerosos ámbitos dentro del área de estudio, podría ser una de las causas que expliquen que el coeficiente de correlación de Pearson no sea más alto con respecto a diferentes variables con una clara implementación espacial, como las estudiadas en este artículo.

Figura 9. Ejemplo de aparente fenómeno de imitación a la hora de colgar banderas y estandartes: entre dos edificios semejantes, uno presenta doce elementos colgantes y el otro ninguno

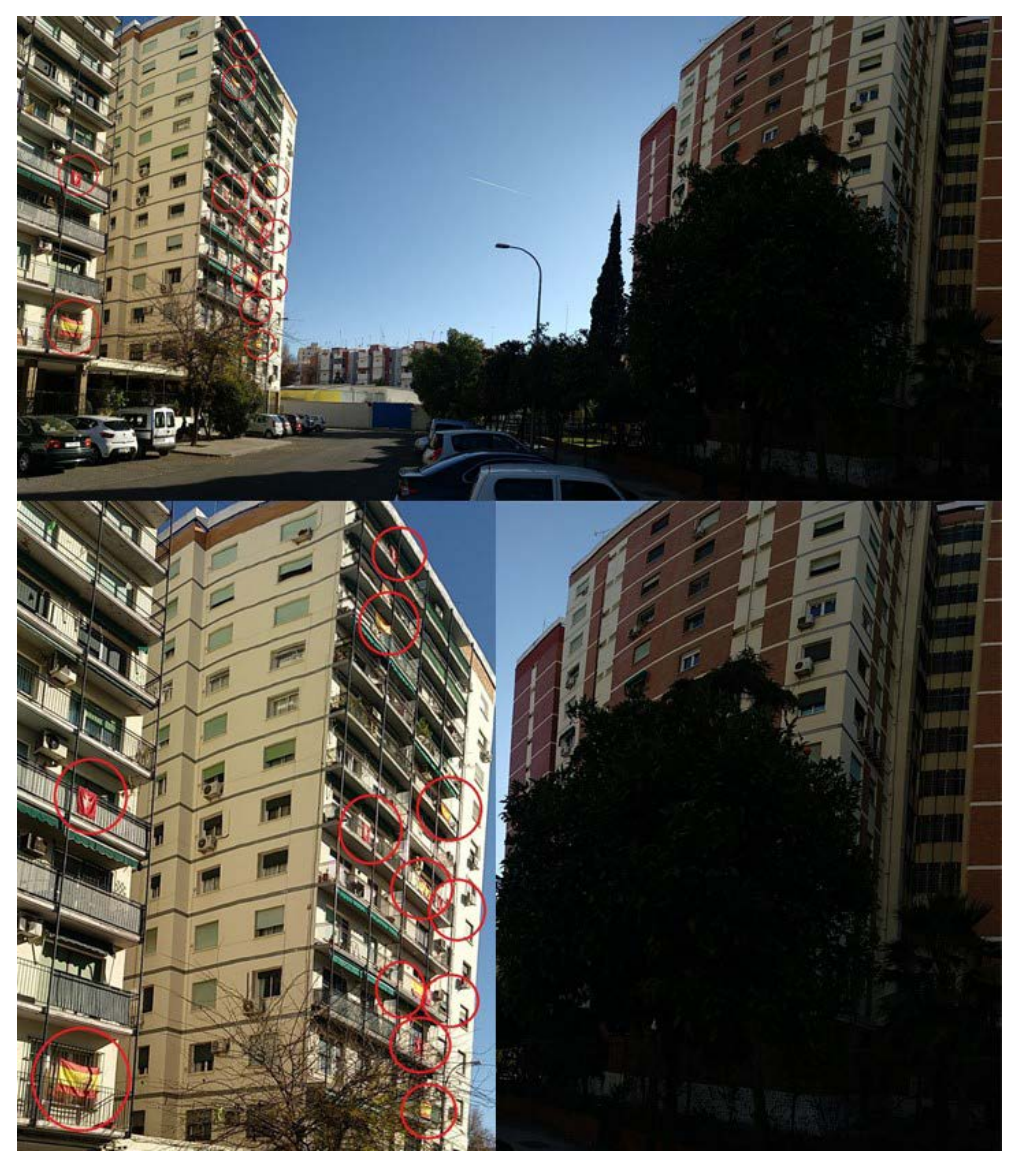

Fuente: elaboración propia 
Pese a que en este trabajo no se ha realizado un análisis de la evolución temporal de la distribución de las banderas, cabe señalar que el elevado número de banderas identificadas en algunos sectores de Sevilla -y en cierto modo, la ausencia de banderas en otros- está en consonancia con las teorías de Lascoumes y Le Galès (2005) sobre la multiplicación de problemas públicos y sobre todo de espacios y actores. En este sentido, los balcones se convierten en un espacio evidente para la reivindicación ideológica. Estas ideas ya se recogen en la bibliografía desde los trabajos de Lefebvre (1974) sobre el significado del simbolismo en la ciudad, para quien "las ideologías no producen el espacio, están él". Lascoumes y Le Galès (2005) aluden igualmente a la modificación de las formas de movilización de los actores sociales. Pese a que se trate de una referencia de 2005, resulta inequívocamente actual al percibirse un cambio en la forma de hacer política y de reivindicar desde la potencia de determinadas imágenes, ya sean percibidas en las calles, o desde las plataformas de amplificación de ideas e influencia en procesos políticos en las que se han convertido las redes sociales (Szwarcberg, 2015; Halberstam \& Knight, 2016). Aun así, en el caso de la ciudad de Sevilla, se da el fenómeno invertido al que plantea Szwarcberg (2015) acerca de la potencia de los símbolos urbanos sobre los barrios obreros, puesto que en este caso no parecen ser las clases trabajadoras aquellas más afectadas por la potencia de imágenes como la de la Figura 5, sino que la imagen se proyectan desde los barrios habitados por la propia burguesía local.

\section{Conclusiones}

El trabajo realizado ha permitido cuantificar e interpretar el fenómeno de la exhibición banderas de España y estandartes de Jesús desde los balcones del municipio de Sevilla. Ambos fenómenos están explicados principalmente por la ideología de los residentes, y en particular con el porcentaje de votos a Vox y al PP, así como a la mayor participación en las elecciones de diciembre de 2018, concordando con la interpretación tradicionalmente hecha acerca de que la mayor movilización electoral se produce por parte de los votantes de derecha. De este modo, esta mayor implicación en la vida política no solo abarcaría el fenómeno de una mayor participación en las elecciones, sino en otros aspectos como la exhibición de simbología nacional, además de católica, coincidente en buena medida en el ámbito de estudio. Del mismo modo, el voto a Adelante Andalucía y PSOE permite explicar, a través de una correlación inversa, la distribución de las banderas de España dentro del municipio objeto de estudio.

Pese a que la religión católica es mayoritaria en España, parece existir una fuerte relación entre la ideología y la exhibición en el domicilio de simbología religiosa, de tal modo que en los barrios con mayor renta y más conservadores se identifican muchos más elementos religiosos que en los barrios obreros. Aunque esta interpretación ideológica es una probable causa de la distribución espacial observada, deberían observarse empíricamente otras cuestiones referidas a la propia distribución 
del catolicismo dentro del municipio, e identificar si existe un agrupamiento entre votantes conservadores, votantes de alto poder adquisitivo, y votantes católicos, aunque todo parezca indicar que sí.

Otros factores de aparente importancia, como el precio medio de la vivienda, o el tamaño de la misma, resultan ser menos relevantes que las cuestiones exclusivamente ideológicas. No obstante, es posible que con variables socioeconómicas espacializadas a un nivel de detalle mayor (idealmente, la renta per cápita por calle), podrían obtenerse resultados diferentes a la hora de interpretar este fenómeno. En cualquier caso, sí parece evidente que el fenómeno de exhibición de ambos tipos de simbología está vinculado con las élites económicas del municipio, tal y como evidencian los resultados obtenidos en cuanto al nivel de estudios y exhibición de banderas, y el precio de la vivienda con respecto a la exhibición de estandartes de Jesús.

Pese a que los valores más altos de exhibición de ambos tipos de simbología por habitante se identificaron en torno al distrito de Los Remedios y en menor medida, al sur de la ciudad y en el sur del Casco Histórico, los modelos de regresión múltiple elaborados mediante diferentes metodologías coincidieron en identificar como única variable predictora el voto a Vox, siendo despreciable la mejora del modelo aportada por otras variables.

El método empleado, pese a prescindir de variables de gran relevancia como la renta per cápita, anteriormente citada, permite describir y explicar una parte importante de la distribución de las banderas de España y estandartes de Jesús. No obstante, existen fenómenos aparentemente psicológicos de gran complejidad, como la imitación en la exhibición de ambos tipos de simbología, que trascienden de las técnicas aplicadas y que probablemente requieran de entrevistas personales para poder interpretarlo. Otra posible razón, relacionada con la anterior, que podría explicar estos fenómenos estaría en la construcción de una identidad de barrio a partir de la exhibición de banderas y estandartes en los distritos más conservadores. En cualquier caso, serán precisos análisis más profundos en el futuro que incluyan entrevistas personales acerca de las motivaciones para colgar estas banderas, que podrán explicar verificar esta idea. El método desarrollado no permite conocer la importancia que eventos políticos como la reacción nacionalista española ante el secesionismo catalán, hayan podido tener en los datos recogidos, puesto que todo el trabajo de campo se realizó en pocos días, sin que exista una serie histórica acerca de la exhibición de esta simbología en los años anteriores.

Agradecimientos: Las/os autoras/es desean expresar su agradecimiento a Kiko Llaneras, del diario El País, por sus consejos sobre algunas fuentes de información empleadas, y a Jaime Jover Báez y Víctor Fernández Salinas por sus sugerencias acerca de numerosas referencias bibliográficas. 
Declaración responsable: Las/os autoras/es declaran que no existe ningún conflicto de interés en relación a la publicación de este artículo. Pablo Fraile Jurado y Miguel Fernández Díaz realizaron el trabajo de campo consistente en el recuento de banderas y estandartes en las calles del municipio de Sevilla, así como en la posterior verificación. Ambos autores filtraron los datos y elaboraron una tabla con la que realizar los análisis espaciales y estadísticos, siendo Miguel Fernández el encargado de elaborar los mapas. Pablo Fraile Jurado realizó la revisión bibliográfica y la redacción del texto. 


\section{Bibliografía}

Arias, S. (2013, December 10). Comienza la campaña "Pon un Niño Jesús en tu balcón". El Comercio. Retrieved from https://www.elcomercio.es/v/20111213/oviedo/comienza-campananino-jesus-20111213.html

Arribas, S. C. (2009). Libertad religiosa del menor y simbología religiosa en la escuela. In Algunas cuestiones controvertidas del ejercicio del derecho fundamental de libertad religiosa en España (pp. 331-359). Madrid: Fundación Universitaria Española.

Arribas, S. C. (2010). Símbolos religiosos en un Estado democrático y plural. Revista Estudios Jurídicos. Segunda Época, 10.

Arthur, C. (2018). From Fretilin to freedom: The evolution of the symbolism of Timor-Leste's national flag. Journal of Southeast Asian Studies, 49(2), 227-249.

Ayuntamiento de Sevilla (2016). Revisión del Mapa estratégico del Ruido del término municipal de Sevilla. Anexo IV. Retrieved from

http://www.sevilla.org/documentos/proteccionambiental/MapadeRuidos/ANEXOIV/40.pdf

Bernardo, F., \& Palma-Oliveira, J. M. (2016). Identification with the neighborhood: Discrimination and neighborhood size. Self and Identity, 15(5), 579-598.

http://dx.doi.org/10.1080/15298868.2016.1178665

Cadenas y Vicent, V. D. (1976). Manual de Vexilología. Madrid: Hidalguía.

Caínzos, M. (2001). Cainzos. Zona Abierta, 96(97), 91-171.

Cannon, B. (2008). Class/Race Polarisation in Venezuela and the Electoral Success of Hugo Chávez: a break with the past or the song remains the same? Third World Quarterly, 29(4), 731748 .

Cañamares Arribas, S. (2006). El empleo de simbología religiosa en España. Boletín mexicano de derecho comparado, 39(116), 317-350.

Cañamares Arribas, S. (2006). El empleo de simbología religiosa en España. Boletín mexicano de derecho comparado, 39(116), 317-350.

Capéans, J. (2018, October 14). Galicia no se asoma a la España de los balcones. La Voz de Galicia. Retrieved from https://www.lavozdegalicia.es/noticia/galicia/2018/10/14/galiciaasoma-espana-balcones/0003_201810G14P8995.htm

Cebrián Echarri, B. (2017, November 10). Y ahora, ¿qué hacemos con la banderas? El País. Retrieved from https://elpais.com/elpais/2017/11/09/opinion/1510253815_254844.html 
CIS (2013). Estudio n 3005. Barómetro noviembre 2013. Madrid: Centro de Investigaciones Sociológicas.

Coski, J. M. (2009). The Confederate battle flag. Cambridge, US: Harvard University Press.

Daniele, L. (2017, June 5). La Iglesia católica sufre el 70\% de los ataques a la libertad religiosa. ABC. Retrieved from https://www.abc.es/sociedad/abci-iglesia-catolica-sufre-70-por-cientoataques-libertad-religiosa-201706031915_noticia.html

Deener, A. (2010). The 'black section' of the neighborhood: Collective visibility and collective invisibility as sources of place identity. Ethnography, 11(1), 45-67.

http://dx.doi.org/10.1177/1466138109346988

Díaz Parra, I. (2009). Procesos de gentrificación en Sevilla en la coyuntura reciente. Análisis comparado de tres sectores históricos: San Luis-Alameda, Triana y San Bernardo (2000_ 2006). Scripta Nova, 13. Retrieved from http://www.ub.edu/geocrit/sn/sn-304.htm

Enguix, B. (2009). Espacios y disidencias: el orgullo LGTB. Quaderns-e de I'Institut Català d'Antropologia, 14, 1-34

Eriksen, T. H., \& Jenkins, R. (Eds.) (2007). Flag, nation and symbolism in Europe and America. London, UK: Routledge.

Europa Press (2018, February 10). Casado pide a "la España de los balcones" ir a las urnas en 100 días para censurar la actuación de Sánchez. Eldiario.es. Retrieved from https://www.eldiario.es/politica/Casado-Espana-balcones-actuacion-

Sanchez_0_866513477.html

Haeberle, S. H. (1987). Neighborhood identity and citizen participation. Administration \& society, 19(2), 178-196. http://dx.doi.org/10.1177/009539978701900203

Halberstam, Y., \& Knight, B. (2016). Homophily, group size, and the diffusion of political information in social networks: Evidence from Twitter. Journal of Public Economics, 143, 73-88.

Hernández, C. (2018, 18 de octubre). Lo que se ve cuando apartas la bandera. Eldiario.es. Retrieved from https://www.eldiario.es/zonacritica/ve-apartas-bandera_6_826327387.html

Hull, R. B., Lam, M., y Vigo, G. (1994). Place identity: symbols of self in the urban fabric. Landscape and urban planning, 28(2-3), 109-120. http://dx.doi.org/10.1016/0169$\underline{2046(94) 90001-9}$

INE (2018). Estadística del Padrón Continuo. Retrieved from https://www.ine.es/dyngs/INEbase/es/operacion.htm?c=Estadistica_C\&cid=1254736177 $\underline{012 \& m e n u=u l t i D a t o s \& i d p=1254734710990}$ 
Jaskulowski, K. (2016). The magic of the national flag. Ethnic and Racial Studies, 39(4), 557573. http://dx.doi.org/10.1080/01419870.2015.1078482

Lefebvre, H. (1974). La producción del espacio. Papers: Revista de Sociología, (3), 219-229.

López, J. (2018, June 2) La bandera de España retorna a los balcones de Jaén tras la moción de censura. ABC de Sevilla. Retrieved from https://sevilla.abc.es/noticias/sevi-bandera-espanaretorna-balcones-jaen-tras-mocion-censura-201806021441_noticia.html

Martinez i Coma, F., \& Van Ham, C. (2015). Can experts judge elections? Testing the validity of expert judgments for measuring election integrity. European Journal of Political Research, 54(2), 305-325. http://dx.doi.org/10.2139/ssrn.2314197

Miralles, X. A. (2015). Nacionalismo español y culturas políticas. El comienzo de una buena amistad. Historia y política: Ideas, procesos y movimientos sociales, (34), 355-381.

Muñoz, J. 2012. La construcción política de la identidad española: ¿ del nacionalcatolicismo al patriotismo democrático? Madrid: Centro de Investigaciones Sociológicas.

Navalón (2018, October 27). La guerra de las banderas. El País. Retrieved from https://elpais.com/elpais/2017/10/15/opinion/1508079817_365327.html

Navarro Ardoy, L. (2016). La nación evitada: identidad nacional en España y discursos de élites de izquierda (Doctoral dissertation, Universidad Pablo de Olavide, Spain). Retrieved from https://www.educacion.gob.es/teseo/imprimirFicheroTesis.do?idFichero=zfWGOX\%2FOdro $\underline{\% 3}$

Observatorio para la libertad religiosa y de conciencia (2017). Ataques a la libertad religiosa en España 2016. Retrieved from http://libertadreligiosa.es/wpcontent/uploads/2017/06/ATAQUES-LR-2016-FINAL-1.pdf

Observatorio para la libertad religiosa y de conciencia (2018). Ataques a la libertad religiosa en España 2017. Retrieved from http://libertadreligiosa.es/2018/05/22/informe-de-ataques-a-lalibertad-religiosa-en-espana-2017/

Palonen, E. (2009). Political polarisation and populism in contemporary Hungary. Parliamentary Affairs, 62(2), 318-334. http://dx.doi.org/10.1093/pa/gsn048

Pareja, M. (2018, December 17). La España de los balcones. Diario de Jerez. Retrieved from https://www.diariodejerez.es/opinion/articulos/Espana-balcones_0_1310268997.html

Perlman, F. (1985). The continuing appeal of nationalism. Detroit, US: Black \& Red.

Podeh, E. (2011). The symbolism of the Arab flag in modern Arab states: between commonality and uniqueness. Nations and Nationalism, 17(2), 419-442. http://dx.doi.org/10.1111/j.1469$\underline{8129.2010 .00475 . x}$ 
Ponte, V. (2008, December 26). Sal al balcón en Navidad. Huelva información. Retrieved from https://www.huelvainformacion.es/huelva/Sal-balcon-Navidad_0_217478547.html

Ramón, E. (2017, November 4). ¿Qué razón psicológica nos impulsa a poner banderas en los balcones? Expansión. Retrieved from

www.expansion.com/sociedad/2017/11/04/59fdb469e2704e2c098b4632.html

Redacción (2008, December 22). Se dispara la demanda de tapices navideños con el Niño Jesús. Religión en Libertad. Retrieved from https://www.religionenlibertad.com/noticias/1625/sedispara-la-demanda-de-tapices-navidenos-con-el-nino-jesus.html

Redacción (2017, October 27). Majadahonda regala a los vecinos banderas de España para los balcones. La Vanguardia. Retrieved from

https://www.lavanguardia.com/local/madrid/20171002/431748437962/majadahonda-regalaa-los-vecinos-banderas-de-espana-para-los-balcones.html

Rodríguez Fouz, M. (2010). Batallas simbólicas. La lucha por el espacio público en Euskadi. Papeles del CEIC, International Journal on Collective Identity Research, (2), 7.

Schatz, R. T., \& Lavine, H. (2007). Waving the flag: National symbolism, social identity, and political engagement. Political Psychology, 28(3), 329-355. http://dx.doi.org/10.1111/j.1467$\underline{9221.2007 .00571 . x}$

Smith, R. L. (1984). Creating neighborhood identity through citizen activism. Urban Geography, 5(1), 49-70. http://dx.doi.org/10.2747/0272-3638.5.1.49

Szwarcberg, M. (2015). Mobilizing poor voters: Machine politics, clientelism, and social networks in Argentina (Vol. 37). Cambridge: Cambridge University Press.

https://doi.org/10.1017/CBO9781316286913

Taylor, R. (1990). Interpretation of the correlation coefficient: a basic review. Journal of diagnostic medical sonography, 6(1), 35-39. http://dx.doi.org/10.1177/875647939000600106

Thornton, K. (1996). The Confederate flag and the meaning of Southern history. Southern Cultures, 2(2), 233-245. http://dx.doi.org/10.1353/scu.1996.0018

Torres Gutiérrez, F. J. (2011). El territorio de los desheredados. Asentamientos chabolistas y experiencias recientes de erradicación en Sevilla. Hábitat y Sociedad, 3, 67-90.

Torres, F. J., Galera, V., Fernández, V., Brivio, F., Chioua, J., Díaz, I., \& González, A. (2011). El Distrito Macarena de Sevilla, migraciones recientes y transformaciones urbanas y sociales. Sevilla: Junta de Andalucía, Consejería de Empleo, Dirección General de Coordinación de Políticas Migratorias. 
Tribunal Supremo (2018). Sala de lo Contencioso-Administrativo. Sección Segunda. Sentencia número 843/2018. Retrieved from

http://www.poderjudicial.es/search/SentenciasDictadas/documento/TS/8323679/20180319

Varela, J. (1994). Nación, patria y patriotismo en los orígenes del nacionalismo español. Madrid: UNED. 